\title{
RIBBON SYNAPSES IN THE DEVELOPING INTACT AND CULTURED ORGAN OF CORTI IN THE MOUSE ${ }^{1}$
}

\author{
HANNA M. SOBKOWICZ, ${ }^{2}$ JERZY E. ROSE, GRAYSON E. SCOTT, AND SUSAN M. SLAPNICK \\ Departments of Neurology, Neurophysiology, and Anatomy, University of Wisconsin, Madison, Wisconsin 53706
}

Received November 16, 1981; Revised March 4, 1982; Accepted March 5, 1982

\begin{abstract}
Over 1000 synaptic ribbons were studied in the intact animal from birth to the 23rd day and over 500 were studied in the isolated organ up to 24 days in culture.

Our findings suggest that synaptogenesis in the cochlea of the mouse occurs mainly postnatally and lasts at least 14 days. Afferent synapses of young cochleas are characterized by round ribbons which are attached to the presynaptic membrane by two rodlets, each surrounded by a discrete triangular density. The postsynaptic density is continuous and coextends with the presynaptic complex. The single layer of vesicles surrounding the dense body of the ribbon is disrupted by the presynaptic densities.

In an afferent synapse of the adolescent animal, the predominant organelle is a plate ribbonoften laminated-which measures on the average approximately $1000 \AA$ wide, $2000 \AA$ tall, and $2500 \AA$ long (one section $=700 \AA$ ). The ribbon is attached to a presynaptic density, arcuate in form; a row of synaptic vesicles is aligned along each side of the arcuate density. The presynaptic membrane forms a trough accommodating the ribbon. The postsynaptic density exceeds the territory of the ribbon. Similar development of the synapse also may be observed in culture.

Structural variability of ribbons (seen especially in culture), clustering of ribbons, multiribbon synapses, and ribbon families seem to be characteristic of early development. The occurrence of ring-like or fenestrated ribbons in the intact adolescent animal suggests a limited life span of the organelle.

A decrease in the ribbon population of the outer hair cells, to about $20 \%$ of the total number, occurs postnatally in the intact animal. A similar decrease occurs also in culture. This implies that the ribbon population is not affected by the efferent influx.

The mature cochlear ribbon appears comparable to those of the retina and some ampullary organs of electric fishes.
\end{abstract}

Synaptic ribbons-formations composed of an electron-dense body surrounded by synaptic vesicles-are characteristic presynaptic organelles in the sensory cells of many species.

The term "synaptic ribbon" was introduced by Sjöstrand (1958) for an electron-dense body which, in the retina, usually forms a thin band. However, in a variety

\footnotetext{
1 This work was supported by National Institutes of Health Grants NS15061, NS12732, and NS2P3-03352. We thank Ms. J. Subervi for culturing the tissues and Ms. J. Lichtenstein for assistance in culturing the tissues and for invaluable help with the preparation of the figures. We are indebted to Ms. C. Dizak for the graphic and three-dimensional reproductions. We thank Mr. T. Stewart for photography of the projector drawings. We warmly thank Mr. J. Holy for the assistance in preparation of the manuscript.

${ }^{2}$ To whom correspondence should be addressed at Department of Neurology, University of Wisconsin, Madison, WI 53706.
}

of sensory cells, the shape of the dense body varies greatly. Because of that, some authors describe "bars," "round bodies," or "synaptic bodies." In this paper, we follow the nomenclature of Sjöstrand and speak of the "synaptic ribbon" regardless of the actual shape of the dense body. We consider the vesicles surrounding the ribbon to be a component of the organelle.

Phyletically, ribbons are old structures. They occur in the photoreceptors of the retina (Cohen, 1963; Dowling, 1968, 1974; Fine, 1963; Gray and Pease, 1971; Matsusaka, 1967; Missotten, 1960b; Sjostrand, 1958) and in the cells of the acousticolateralis system (Barets and Szabo, 1962; Bodian, 1978; Flock, 1965; Gleisner and Wersäll, 1975; Hama, 1965; Hama and Saito, 1977; Lowenstein and Osborne, 1964; Pomés-Delaveuve, 1964; Roberts and Ryan, 1971; Smith and Sjöstrand, 1961a, b; Takasaka and Smith, 1971; Tanaka and Smith, 1978; Wersäll et al., $1965,1967)$ in fishes, amphibians, birds, and mammals. 
They also have been described in the electroreceptors of the ampullary organs and in the receptors of the tuberous organs of some fishes (Derbin, 1970; Lissman and Mullinger, 1968; Mullinger, 1964; Roth and Tscharntke, 1976; Szabo and Wersäll, 1970; Szamier and Wachtel, 1970). They have been noted as well in some cells of invertebrates (Boeckh et al., 1970; Osborne, 1966; Steiger, 1967; Wood et al., 1977).

As a rule, synaptic ribbons in mammals occur in the receptor cells. However, their presence in the bipolar cells of the retina (Dowling and Boycott, 1965; Missotten, 1960a) and in the nonreceptor cells of the pineal body (Krstic, 1976; Iues, 1971; Wolfe, 1965) is well established.

In the mammalian organ of Corti, synaptic ribbons in hair cells were first described by Smith and Sjöstrand (1961a). Since synaptic vesicles appear to assemble exclusively around the electron-dense body, it seems likely that synaptic ribbons indicate the only loci in the hair cell where conventional chemical afferent synapses occur. However, little is known about the role that they play in the formation of afferent synapses. We therefore thought it to be of particular interest to study the morphology and structural variations of the ribbons and the synaptic arrangements during postnatal development of the ear. We chose the mouse because its organ of Corti, quite immature at birth, develops postnatally for about 3 weeks.

Our findings are based on studies of normal and cultured sectors of the organ of Corti. The latter usually were explanted at birth and grown in vitro up to several weeks (Sobkowicz et al., 1975, 1980). The cultured sectors permit assessment of the development of hair cells and their innervation in tissue which is isolated from the rest of the organism and deprived of the entire efferent inflow of central origin.

\section{Materials and Methods}

Mice (HA/ICR strain) were obtained from SpragueDawley.

Twenty-eight animals (ages, 1 through 12 days; 14, 16, and 18 days; and 21 through 23 days) were studied. For electron microscopic examination, the animals were anesthetized by cooling, and the cochleas were dissected rapidly in a fixative consisting of $1 \%$ paraformaldehyde and $2.5 \%$ glutaraldehyde in $0.1 \mathrm{~m}$ Sorenson's phosphate

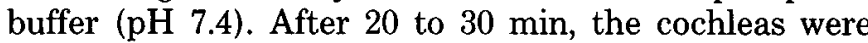
transferred to $2.5 \%$ glutaraldehyde in the same buffer for the next $30 \mathrm{~min}$ and then rinsed in the buffer for about $20 \mathrm{~min}$. After rinsing, the pieces were transferred to $1 \%$ osmium tetroxide for $1 \mathrm{hr}$, dehydrated in ethanol, and embedded in Durcupan. Thin sections were stained with lead citrate.

Observations on cultures were made on 25 explants of the organ of Corti of the newborn mouse maintained in vitro up to 24 days using the techniques previously described (Sobkowicz et al., 1975) and modified as follows. The $\mathrm{pH}$ of the feeding medium was adjusted initially to approximately 6.8 and was increased gradually to 7.2 over a period of 3 to 10 days. Within $48 \mathrm{hr}$ after explantation, the cultures were transferred from the Maximow slide assembly to Corning Pyrex roller tubes, closed with rubber stoppers, and rotated in a roller drum (15 $\mathrm{min} /$ cycle). On the 3rd or 4th day, permeable stoppers were introduced to provide free air- $\mathrm{CO}_{2}$ exchange. Cultures were transferred temporarily from roller tubes to Maximow slide assemblies for daily photography and eventually were fixed for electron microscopic studies according to the technique described previously (Guillery et al., 1970).

\section{Results}

Distribution patterns. It should be stressed that the presence of a ribbon does not immediately imply that a synapse has been formed, for a ribbon may adjoin structures other than a nerve fiber or it may lie free in the cytoplasm. Moreover, at least in the early postnatal period, a ribbon frequently is apposed to an afferent nerve fiber that does not show any postsynaptic specialization. We shall consider these facts elsewhere when we report on synapse formation.

Synaptic ribbons are already present in the newborn mouse, but their distribution pattern in the young and adolescent animal differs significantly. While maturation is a continuous process, it is often useful to speak of observations pertaining to younger or older age groups. For the sake of simplicity, we will refer to animals up to 12 days of age as young and to those 2 to 3 weeks old as older or adolescent.

The distribution of synaptic ribbons as a function of age is shown in Figure 1. The data show ribbon counts in radially oriented sections through the organ of Corti, where, as a rule, there is a ratio of one inner to three outer hair cells. Therefore, one could expect the counts in the inner and outer hair cells to constitute, respectively, $25 \%$ and $75 \%$ of a given age sample if the proba-

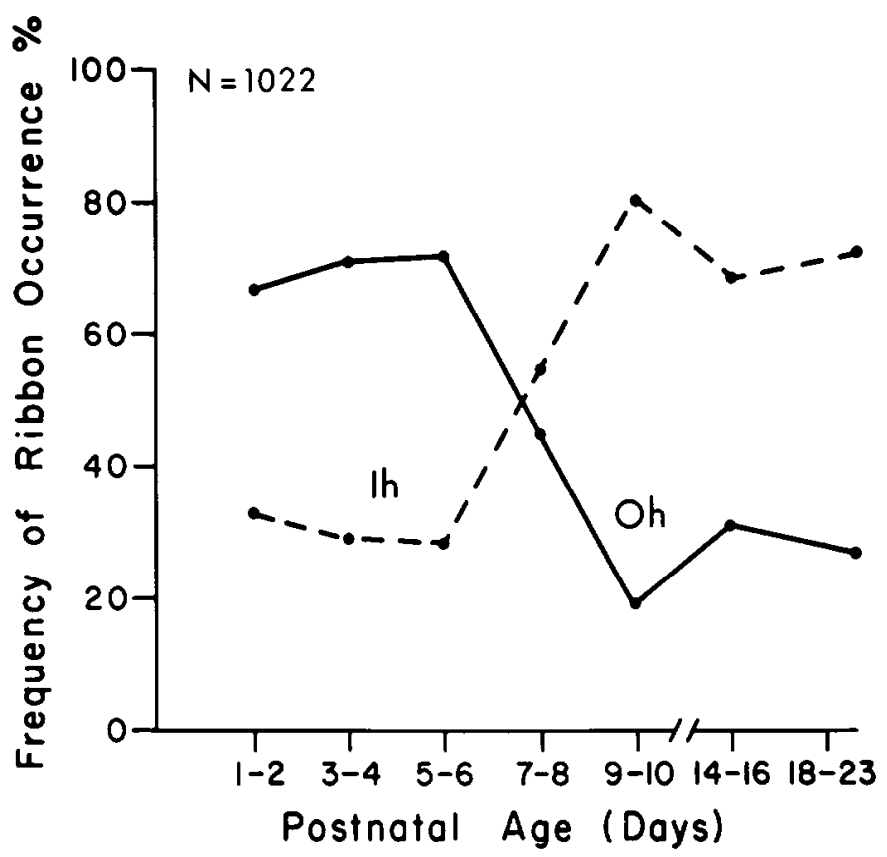

Figure $1 .^{3}$ Distribution of ribbons in the inner and outer hair cells as a function of age in an intact animal.

\footnotetext{
${ }^{3}$ The abbreviations used are: DIV, days in vitro; Ih, inner hair cell; Oh, outer hair cell; $\mathrm{S}$, section number (given only if not all consecutive sections are shown).
} 

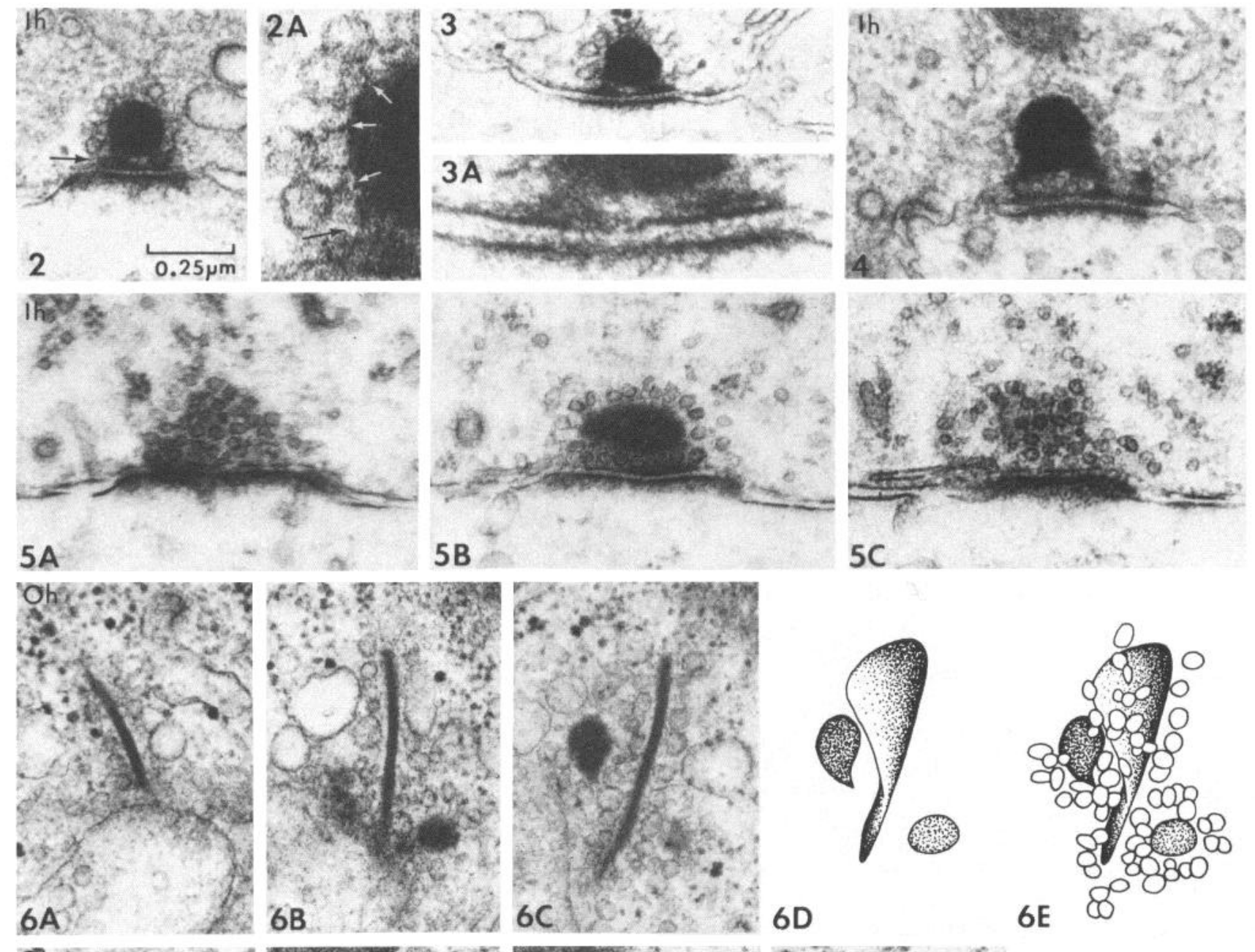

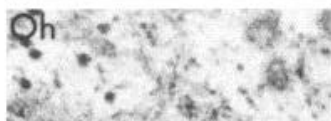
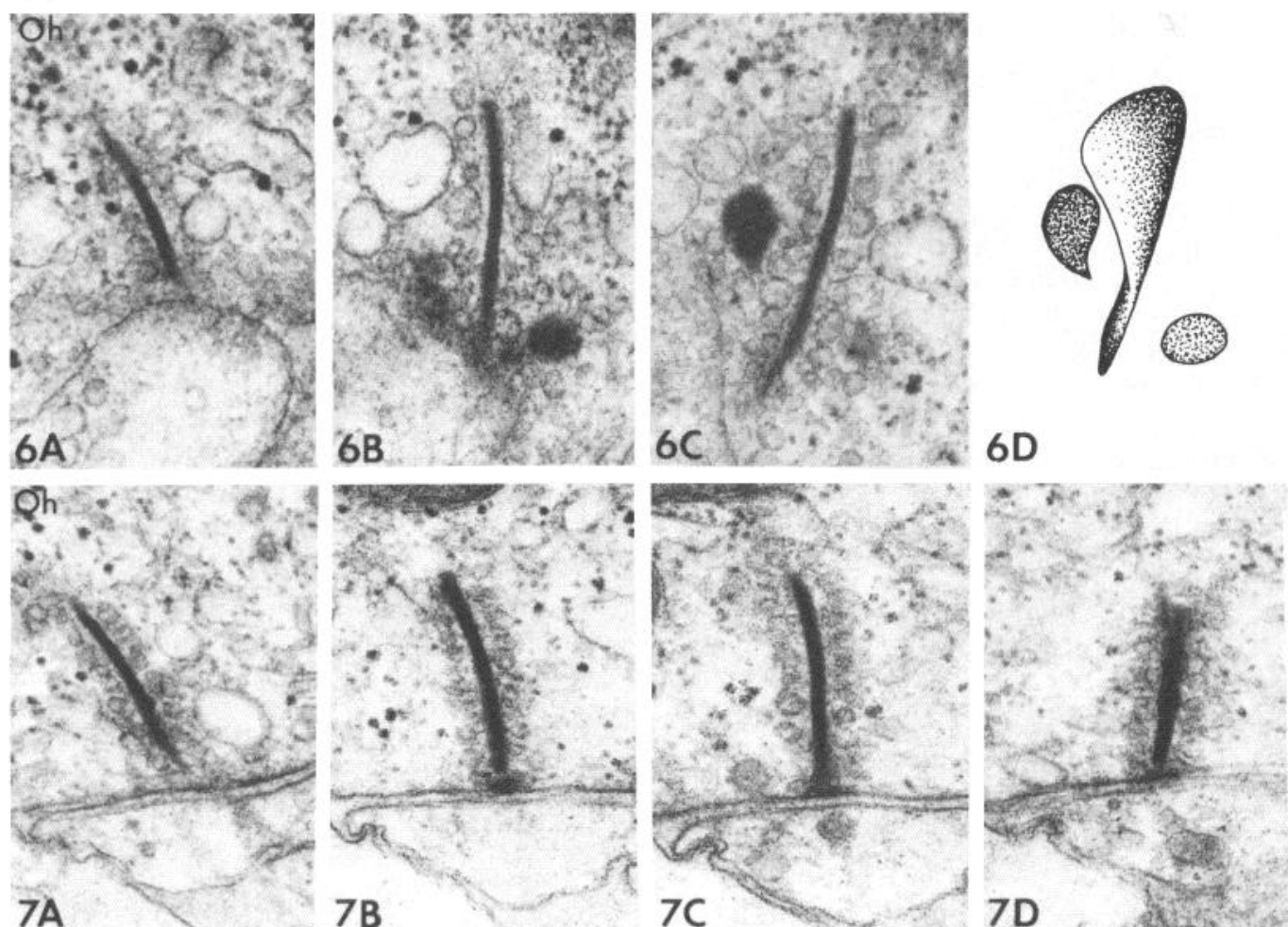

$6 \mathrm{E}$
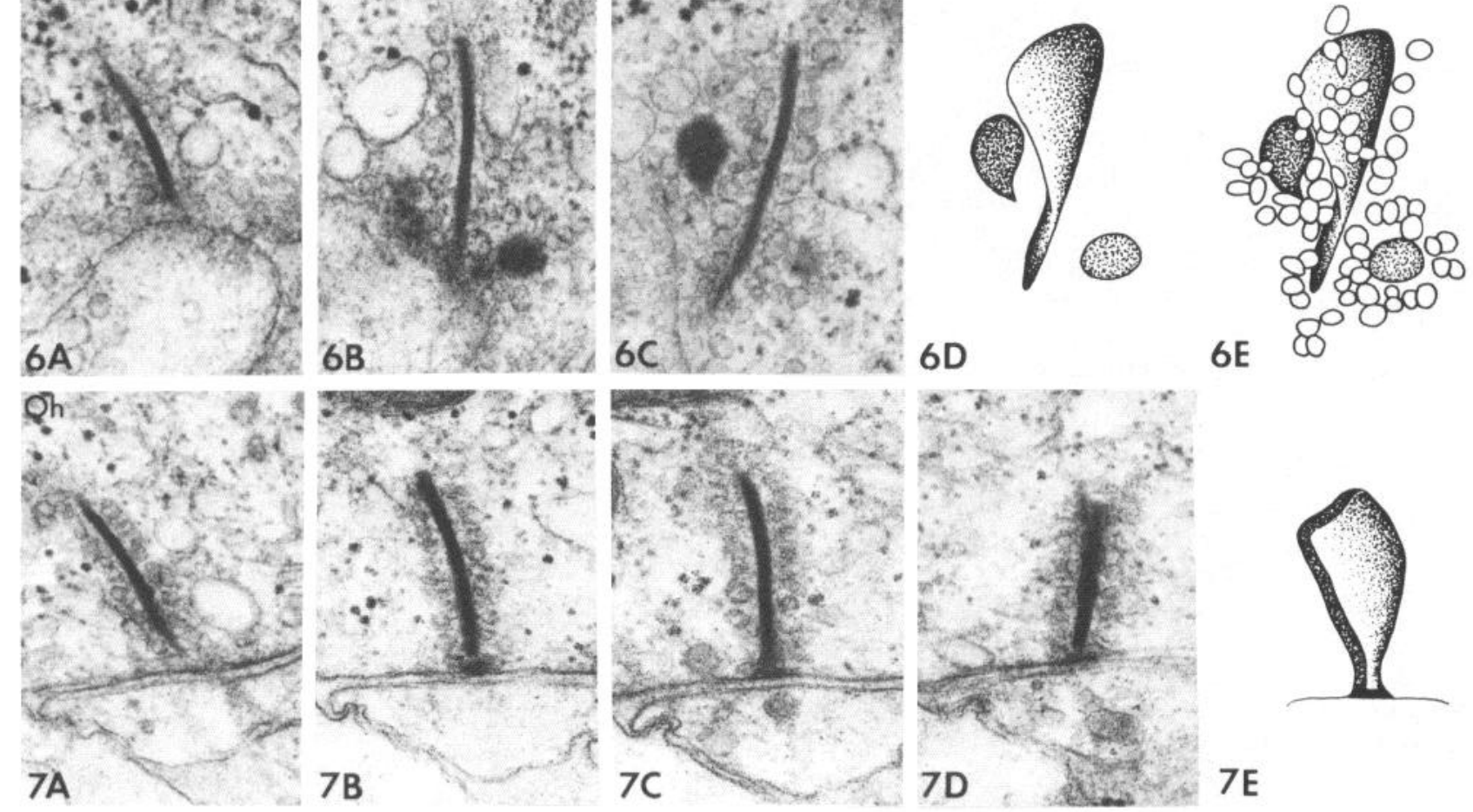

7B
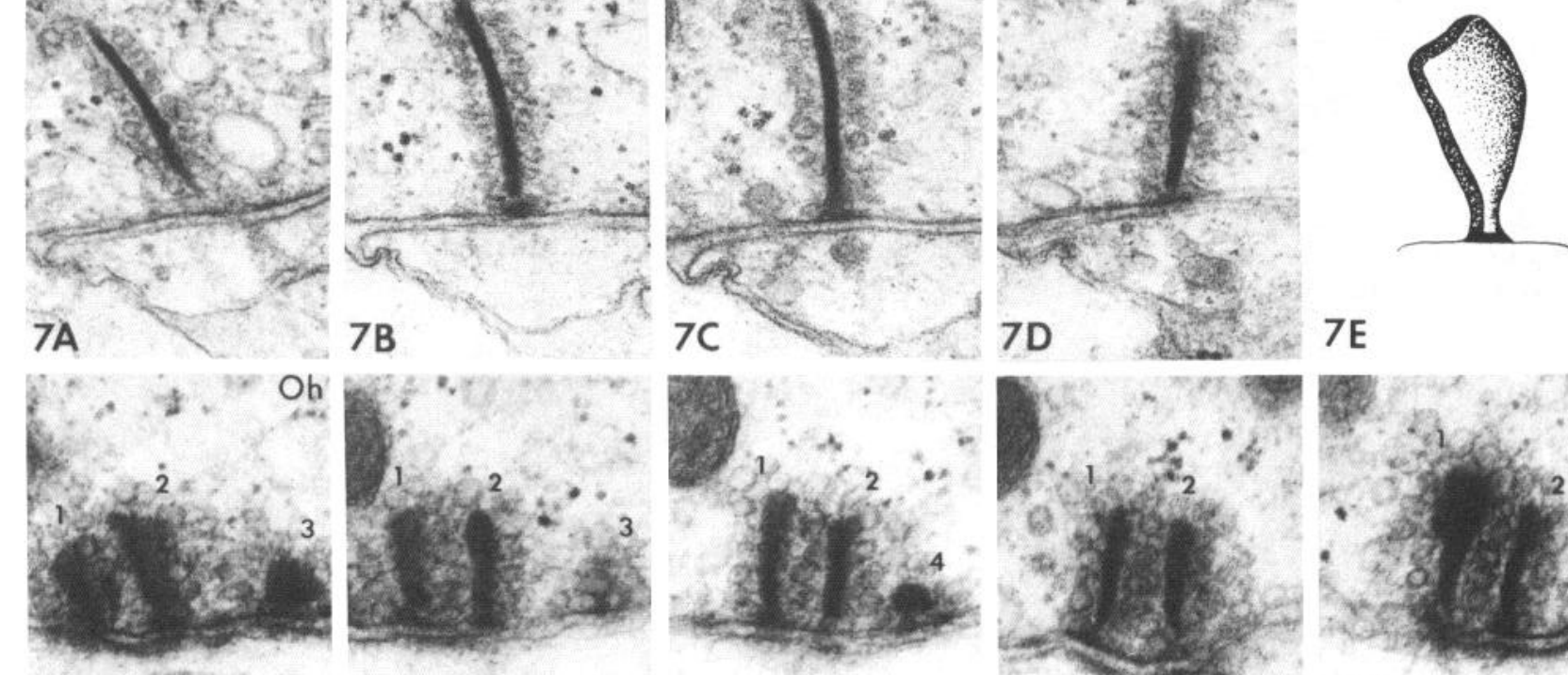

$7 E$
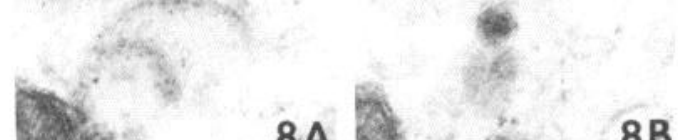

$8 \mathrm{~B}$
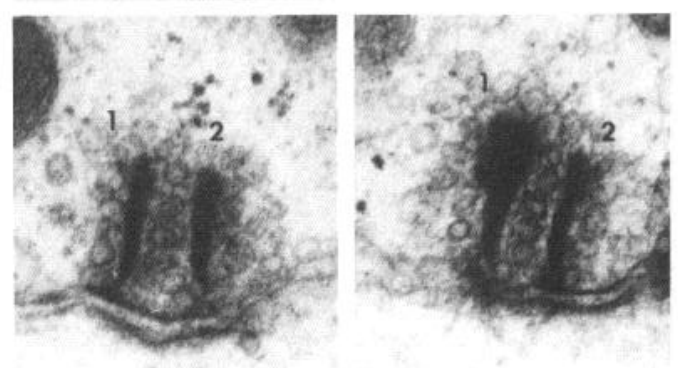

8A he

$8 \mathrm{C}$.

8D

$8 E$

Figures 2 to 8 
bility of a ribbon occurrence were the same for both types of hair cells. In fact, during the first 5 days, about $70 \%$ of the ribbons occur in the outer hair cells and only $30 \%$ occur in the inner hair cells. However, between the 6 th and 10th days, the ribbon population in the outer hair cells decreases greatly. The outer hair cells, at about the time when they receive efferent endings (around 9 days), generate only about $20 \%$ of the ribbon population. An extensive search often is required to find a ribbon in the outer hair cells in older animals. Ribbons in cultured cochleas show a similar trend. In the first few days in vitro, most ribbons occur in the outer hair cells, whereas older cultures display ribbons mainly in the inner hair cells. Thus, the decrease of the ribbon population in the outer hair cells is not influenced by the incoming efferent fibers since it also occurs in the cultured organ, which is devoid of efferent innervation.

Structure of the ribbon synapse in the young cochlea. During the first 12 postnatal days and in cultures of corresponding ages, most ribbons of both inner and outer hair cells tend to have a circular or oval outline.

Figure 2 illustrates an afferent synapse in a 9-day intact animal; Figure 3 shows one in a 6 -day culture. Both synapses are closely comparable with the exception of the postsynaptic surface which, in culture, is flat. The dense body appears homogeneous or granular. Typically, the round ribbon connects with two triangular presynaptic densities by conical rodlets, which may appear filamentous or tubular (Figs. 2 to 4 ). Symmetrical attachments of the ribbon to the cell membrane often seem to flatten the base of the ribbon (Fig. 4). The presynaptic membrane is electron dense and usually straight. The cleft contains clumps of electron-dense material (Fig. $3 A$ ).

A single layer of vesicles commonly surrounds the body of the ribbon and characteristically is interrupted by presynaptic densities (Figs. 2 to 4 ). The vesicles appear attached to the ribbon by fine strands (Fig. 2A, white arrows). Sections showing only the vesicular cap indicate that the vesicles may be arranged in an impressively regular pattern (Fig. 5, $A$ and $C$ ). Significant differences in size often are present among individual vesicles of the same ribbon (Fig. $6 E$ ) and among the vesicles of different ribbons (Figs. 6 and 7 ).

Attachments of vesicles to the dense body of the ribbon (Fig. 2A) have been observed in the retina by Foos et al. (1969), Gray and Pease (1971), Raviola and Gilula (1975), and Spadaro et al. (1978). Similar attachments were noted in ribbons of the lateral line (Mullinger, 1964; Pomés-Delaveuve, 1964) and frog labyrinth (Gleisner et al., 1973); recently Saito described them in mammalian cochlear hair cells. Osborne (1977) suggests that filamentous connections are present not only between the electron-dense body of the ribbon and the vesicles but also among the vesicles themselves.

In contrast to the discrete presynaptic densities, the postsynaptic density is continuous and nearly coextends with the territory of the ribbon (Figs. 2 and 3).

In all specimens, synaptic ribbons vary greatly in size. The diameter of the round profiles ranges from 0.03 to $0.3 \mu \mathrm{m}$. There is a trend for ribbons to be larger with age. Serial sections indicate that, if the vesicular layer is included in the measurement, a round ribbon usually extends through 1 to a few sections. For example, 134 ribbons in the apical turn of a 6 -day animal showed that a ribbon extended on the average through 2.2 sections. In this sample, ribbons of inner (31) and outer (103) hair cells did not clearly differ in size, extending on the average through 2.0 and 2.3 sections, respectively.

Structural variants in the young cochlea. Although, in young cochleas, the round profiles dominate the ribbon population, strikingly different forms occasionally occur. Two thin plate ribbons are shown in serial sections and reconstructions in Figures 6 and 7. Both plates are about $0.026 \mu \mathrm{m}$ thick. The ribbon in Figure 6 forms a crescent about $0.7 \mu \mathrm{m}$ high; the one in Figure $7 E$ is fan-like and is about $0.45 \mu \mathrm{m}$ high. Their full dimensions are not known, since both series are incomplete. Such tall plates, not described previously in the organ of Corti, greatly resemble the "rod synaptic lamellae" seen in the retina by

Figure 2. Afferent synapse in a young cochlea of a 9-day animal (midtum). $A$ is an enlargement, $\sim 3$ limes, of the ribbon segment shown in Figure 2. The spheroid ribbon is anchored to the presynaptic membrane by two rodlets surrounded by discrete presynaptic densities; the arrow in Figure 2 points to the left density and the black arrow in $A$ points to a rodlet. Synaptic vesicles are attached to the dense body of the ribbon by fine threads $(A$, white arrows). The postsynaptic site of the afferent fiber is slightly elevated-an early sign of synapse maturation-but both presynaptic and postsynaptic membranes are straight. The postsynaptic density coextends with the presynaptic complex. The scale bar applies to all figures shown on the plate unless otherwise indicated.

Figure 3. Ribbon synapse in a 6-day culture (apex; M140-9). $A$ is an enlargement, $\sim 3$ times, of the base of the ribbon shown in Figure 3. Both presynaptic densities are triangular. Note, on the right, an electron-lucent line between the presynaptic density and membrane, a feature commonly seen in the adolescent animal. The presynaptic and postsynaptic membranes are electron dense and straight. The cleft contains clumps of electron-dense material.

Figure 4. A large ribbon and a small companion in a double ribbon synapse in a 6-day culture (apex; M140-9). Both ribbons share the postsynaptic density.

Figure 5. Three consecutive sections $(A$ to $C$ ) of a ribbon in an 18-day animal illustrating the cap of vesicles surrounding the dense body (midturn). The vesicles display a regular chain link arrangement. The ribbon, presumably cut longitudinally, appears as a plate about $0.3 \mu \mathrm{m}$ long.

Figures 6 and 7. Serial sections and graphic reconstructions of two plate ribbons in a 6-day culture (apex; M140-9). Two round ribbons accompany the plate ribbons in Figure $6, B$ and $C$. Synaptic vesicles in Figure $6 E$ are reconstructed according to their actual size. 'The plate ribbon in Figure 7 is attached by a single presynaptic density.

Figure 8 . Serial sections ( $A$ to $E$ ) through a multiribbon synapse in a 2-day animal (base). Two plate ribbons ( 1 and 2 ) extend through at least 5 sections, ribbon 3 extends through at least 2 sections, while small spherical ribbon 4 is seen only in 1 section. 

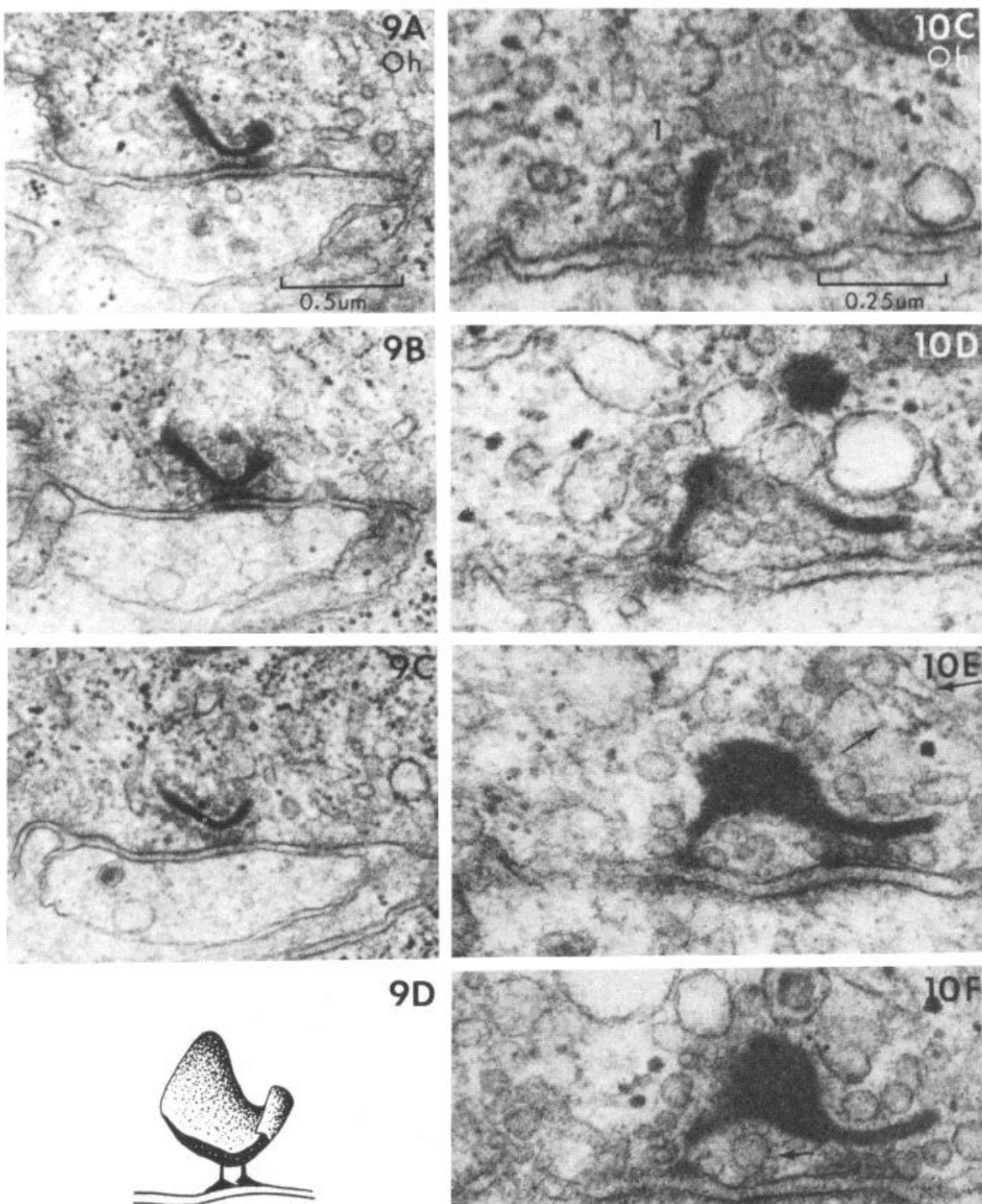

9D
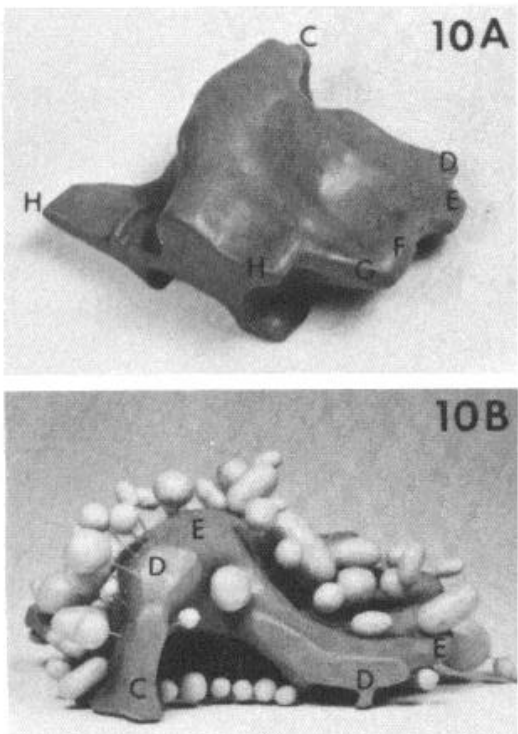
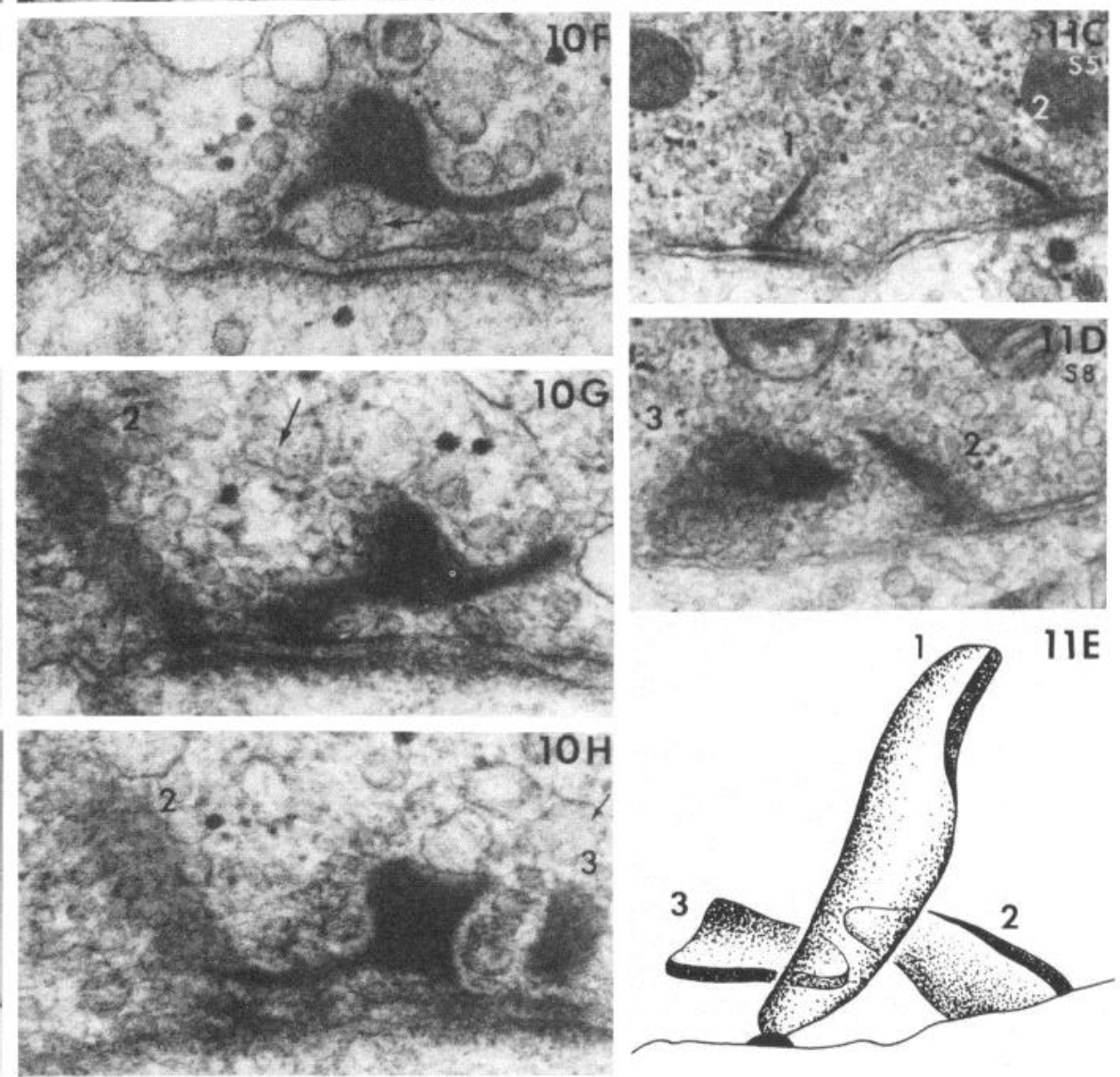
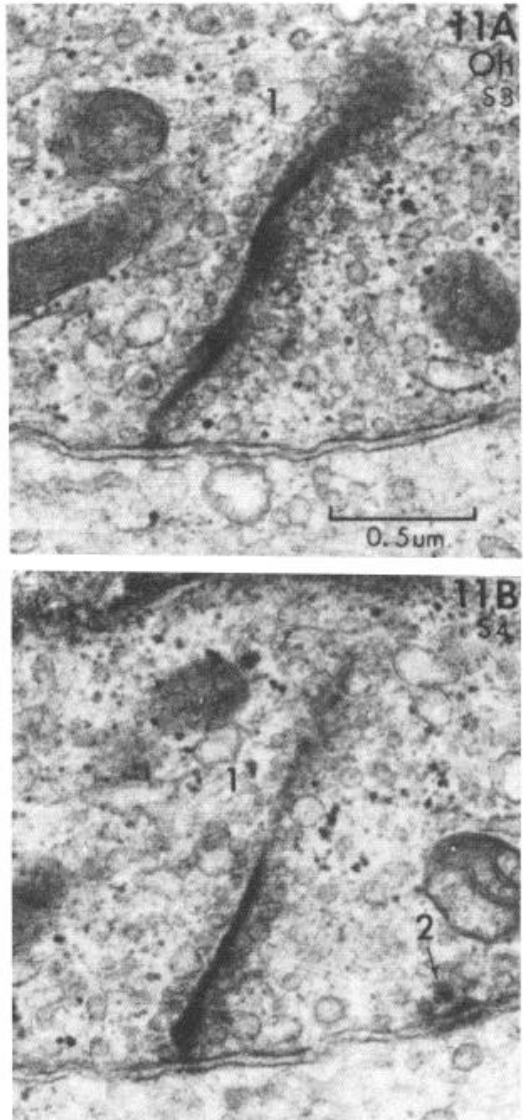
Ladman (1958). Thus far, we observed such ribbons only in culture; rather shorter plates tend to occur in the intact animals. Figure 8 illustrates, in a 2 -day animal, two short plates which extend through at least 5 successive sections. The tall and short plates are similar in that both are bounded by chains of vesicles of which two rows rest on the cell membrane on either side of the presynaptic density. Round and plate ribbons may occur in close proximity to each other or may even be components of the same synapse (Figs. 6 and 8).

A variant of a thin plate ribbon and its reconstruction are shown in Figure 9, $A$ to $D$. The central region of the plate is anchored to the presynaptic densities by two fine strands. The mode of attachment of a ribbon to the presynaptic membrane appears to influence its shape; here, the plate ribbon is curved.

Exceptionally, a thin plate may protrude like a wing from the bulk of the ribbon (Fig. 10, $A$ to $H$ ). We have only 6 serial sections of this unusual ribbon found in a 6 day culture. In Figure 10, $A$ and $B$ show two views of the ribbon model. The ribbon is attached to the membrane by fine ridges; the one on the left side fuses with a discrete triangular presynaptic density (Fig. 10, $E$ and $F$ ), and two fibrous strands seem to link the right wing with the presynaptic membrane (Fig. 10, $D$ to $F$ ).

The wings of the ribbon resemble the crossbar of the "T-bar" of some insect synapses (Boeckh et al., 1970; Lamparter et al., 1969; Trujillo-Cenóz, 1969), for the wings tend to lie parallel to the cell membrane and the distance between the wing and the cell membrane allows the passage of only one layer of vesicles. The vesicle field underneath the wings is therefore one vesicle tall and as wide and long as the wing itself. It appears that the shape of the ribbon determines the area of apposition of the synaptic vesicles to the presynaptic membrane.

In Figure $10 B$, the vesicles are reconstructed according to their actual size. They form a heterogeneous population. Those underneath the ribbon are round, small, and relatively uniform; those capping the ribbon are either round or flat, and their size varies greatly. Some of the profiles of the synaptic vesicles seem to be budding off from smooth endoplasmic reticulum (Fig. 10, E, G, and $H$, arrows). An apparent continuity between the walls of the endoplasmic reticulum and the membrane bounding the synaptic vesicles was noted by Ladman (1958), Thornhill (1972), and Hama and Saito (1977).

Multiribbon synapses and clustering of ribbons. Synaptic ribbons in the adult animal usually are pictured as solitary structures. However, during postnatal develop- ment, several ribbons may participate in the formation of a single synapse and a number of ribbons may cluster over a very restricted territory.

We shall say that a multiribbon synapse is present if 2 or more ribbons share a postsynaptic density. Such synapses usually are formed by closely spaced ribbons whose vesicles tend to intertwine. In the young animal up to about 7 days of age, as many as 4 ribbons may occur in a single synapse, whereas in older animals, a synapse usually contains no more than 2 ribbons. Multiribbon synapses are found in culture (Figs. 4 and $10 \mathrm{H}$ ) as well as in the intact animal (Fig. 8).

If neighboring ribbons are apposed to separate postsynaptic densities, we say that a ribbon family is formed. Figure 11 shows a family of 3 plate ribbons extending through 9 sections. The plates are skewed toward each other.

During the early developmental period, ribbons tend to occur in clusters regardless of whether a postsynaptic density is present. Figures 12 and 13 show graphic reconstructions of serial sections through the receptor pole of two outer hair cells in two intact animals. The areas of hair cell apposition to nerve fibers $(A$ and $B)$ are stippled. The length of apposition is reconstructed on the assumption that the sections were $0.07 \mu \mathrm{m}$ thick. The ribbons are shown from above (i.e., the outlines depict only their length and width). Individual ribbons are identified by numbers. All ribbons shown in Figure 12 are shown in the electron micrographs in Figure 14. Figure 15 illustrates ribbons selected from the population pictured in Figure 13.

Figure 12 shows a reconstruction of 10 consecutive sections from a 2-day animal. A cluster of 12 ribbons occupies a limited area over fiber $B$, whereas no ribbons at all occur in conjunction with fiber $A$. It appears that the occurrence of a ribbon is not determined by the mere apposition of a fiber to the hair cell membrane.

Ribbons 5, 10,11, and 12 (Fig. 14, $A$ to $D$ ) are not associated with a postsynaptic density but form only presynaptic complexes. Each ribbon extends through 2 to 4 sections; round and plate forms occur concurrently.

Figure 13 illustrates the distribution of another 12 ribbons in a 6 -day animal. All ribbons, with the exception of 3 and 4 (Fig. 15, $B$ to $G$ ), are grouped in pairs or triads. They are distributed through 29 sections, hence over a substantially larger area than that occupied by the ribbons in the 2-day animal.

It is our impression that the pattern shown in Figure 13 reflects a more mature state than the clustering shown

Figures 9, 10, and 11. Serial sections and reconstructions of several unusual ribbons seen in culture. 6 DIV (apex; M140-9).

Figure 9. A unique example of a plate ribbon with double attachments to the cell membrane.

Figure 10. Multiribbon synapse. The central ribbon (1), extending through the 6 sections shown ( $C$ to $H$ ), has been reconstructed, and two views of the model are depicted in $A$ and $B$. The individual sections of the model are identified by letters corresponding to those of the micrographs. On either side of the main body, there is a wing-like extension that is attached by fine threads to the presynaptic membrane or presynaptic density. Synaptic vesicles underneath the wings are more uniform in size than those above the dense body; they form a layer one vesicle thick. The sigma form in $F$ (arrow) is suggestive of a vesicle either opening to the membrane or pinching off from its surface. $E, G$, and $H$ may suggest that some of the vesicles are budding off from the surrounding smooth endoplasmic reticulum (arrows). $G$ and $H$ show two additional ribbons (2 and 3 ) of the complex. $D$ shows an electron-dense round body, without surrounding vesicles, lying free in the cytoplasm.

Figure 11. A rare example of a ribbon family composed of plates. The ribbons are skewed toward each other. Ribbon 1 is $\sim 1.6$ $\mu \mathrm{m}$ high, the tallest ribbon in our material. Note the vesicles covering ribbon $3(D)$. 


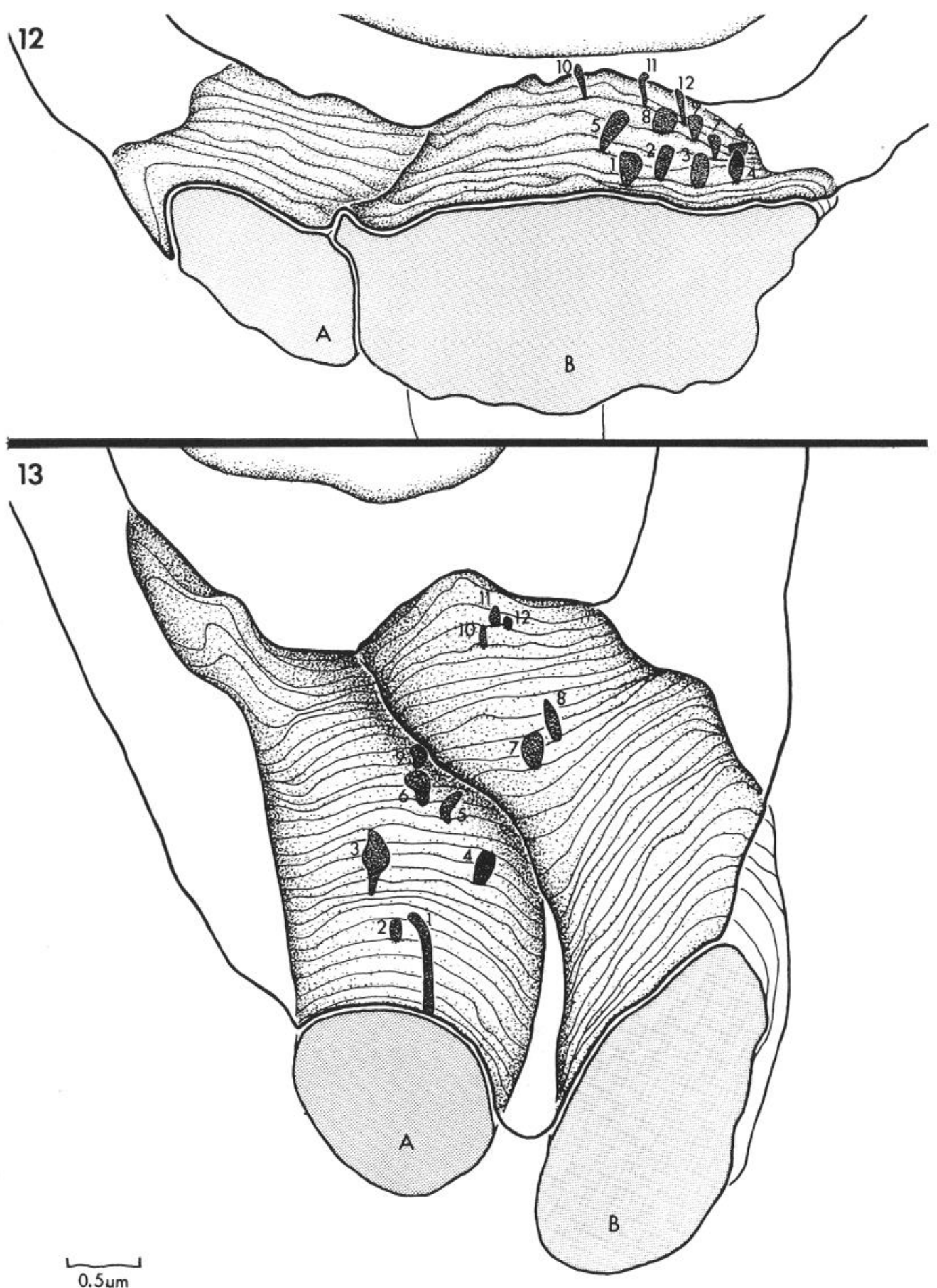

Figure 12. Receptor pole of an outer hair cell in a 2-day animal showing the distribution of synaptic ribbons: graphic reconstruction of 10 consecutive sections. Ribbons are identified by numbers. The stippled regions indicate the area of nerve fiber-hair cell apposition. Note that the 12 ribbons adjoining fiber $B$ are clustered in a restricted area, while no ribbons at all adjoin fiber $A$.

Figure 13. Receptor pole of an outer hair cell in a 6-day animal. Reconstruction conventions are as in Figure 12. Here, there are 12 ribbons in 29 sections. The ribbons tend to group in pairs or triads.

Figure 14. The 12 ribbons drawn in Figure 12 are illustrated here. Ribbons 5, 10, 11, and 12 are not associated with a postsynaptic density and only form presynaptic complexes.

Figure 15. $A$ shows the apposition of fibers $A$ and $B$ (from Fig. 13) to the hair cell membrane. $B$ to $G$ illustrate serial sections through ribbons 3 and 4 , which are rare examples of spheroid ribbons with a single attachment site. Ribbon 3 extends through at least 6 sections and has the shape of a spindle. Note that the ribbon is attached to the presynaptic density along its entire length by a thin ridge. 

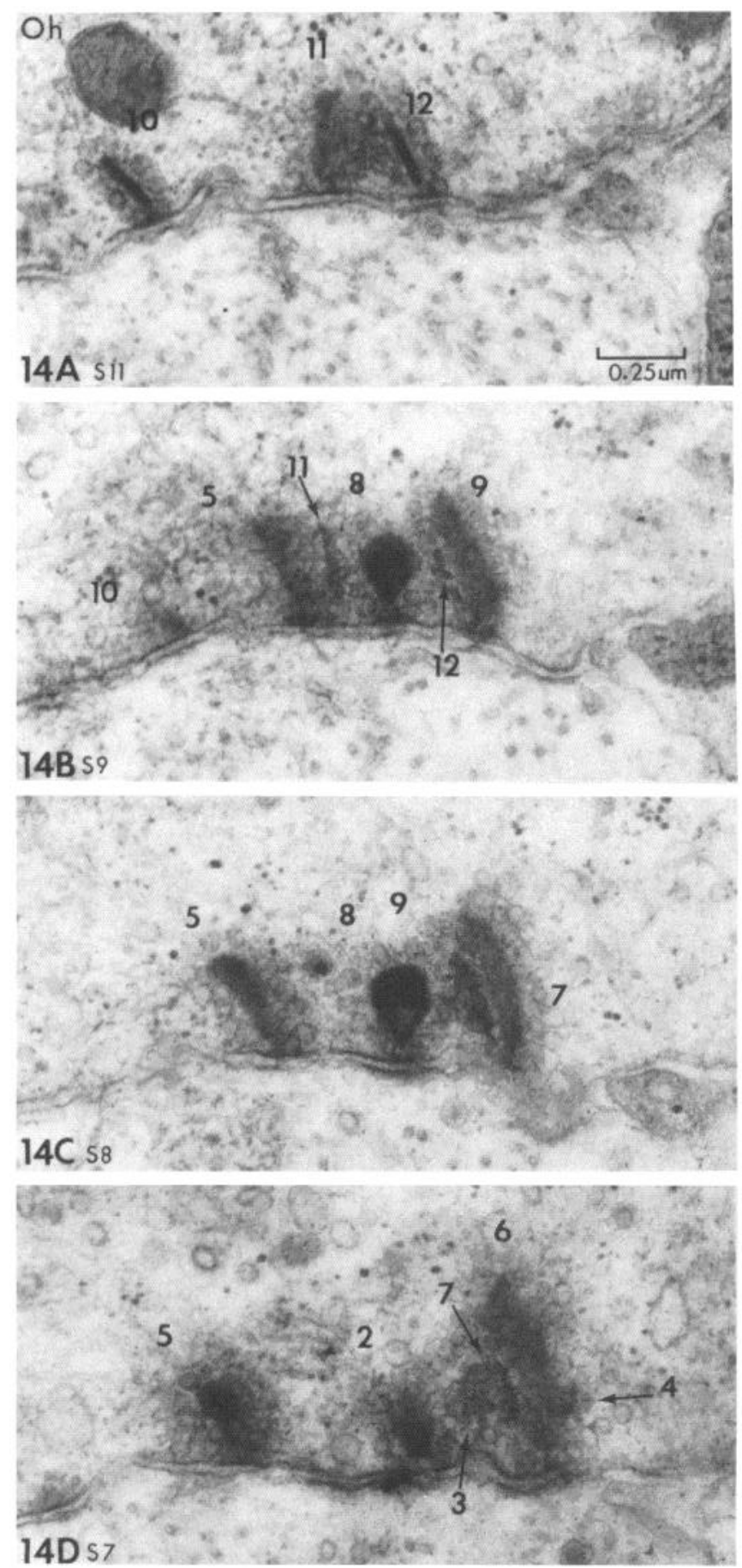

$14 E$ S5
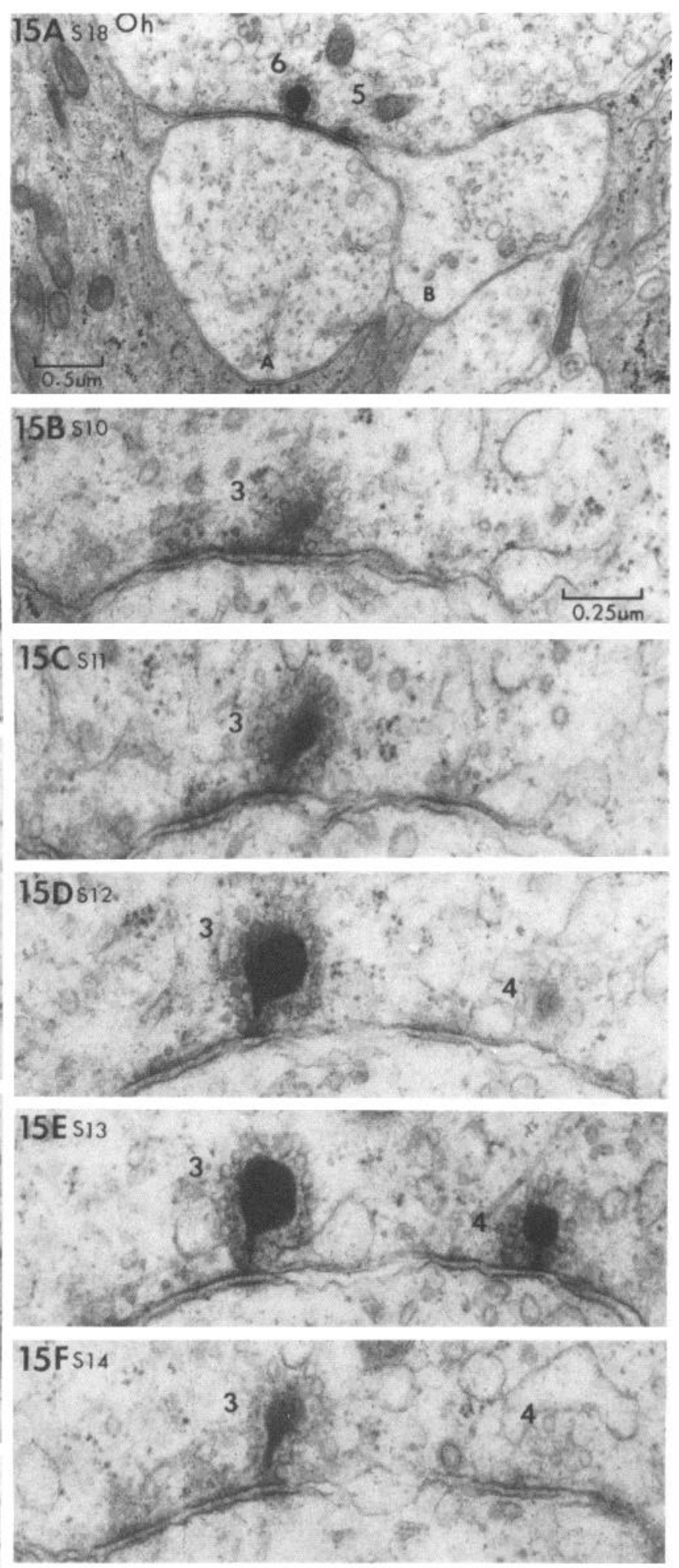

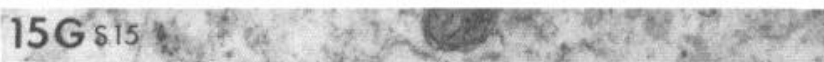

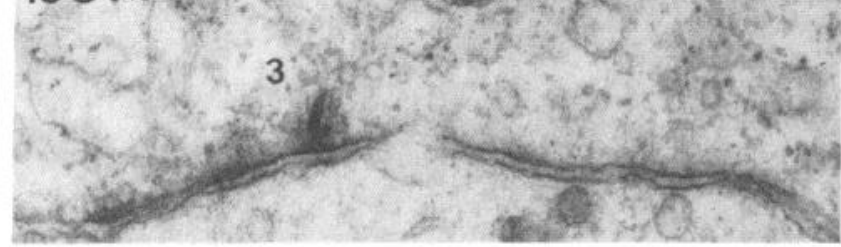


in Figure 12. In our material, a double ribbon synapse is present in the adolescent animals in about $20 \%$ of all synapses.

In Figure $15, B$ to $G$ show serial sections through ribbons 3 and 4 . Ribbon 4 is a rare example of a spheroid form with a single attachment to the presynaptic membrane. Spindle-shaped ribbon 3 is attached to the presynaptic membrane along its entire length by a thin ridge. This shape may be an intermediate form between young spherical and adult plate ribbons.

Structure of the ribbon synapses in the adolescent cochlea. About 14 days are required for development of features that characterize the synapse of older animals (Figs. 16 to 25 ).

A fairly obvious age-dependent feature is the shape of the ribbon. In Figure 16, the ratio of the long to short axis of a ribbon is plotted on the abscissa. The ordinate indicates, at each point, the percentage of ribbons that displayed a ratio up to and including the stated value. Age is the parameter. As stated previously, in the first 10 days and in cultures of corresponding age, most ribbons have a circular or oval outline. In over $60 \%$ of the ribbons, the long and short axes do not differ by more than $10 \%$ (Fig. 16, $A$ and $B$ ). In the adolescent animal, elongated profiles largely replace the rounded forms (Fig. 16C). The shift in form seems related to the way that the organelle is attached to the cell membrane. We shall elaborate on this relationship later in this section.

The adolescent ribbon tends to be a plate approximately $1000 \AA$ wide and $2000 \AA$ tall $(N=162)$. With age, ribbons become longer; data from serial sections of 23 ribbons show that they extend, on the average, through 3 to 4 sections ( 2100 to $2800 \AA$ ). Examples of ribbons cut lengthwise are shown in Figures 5 and 21.

Another feature of ribbons in older animals is the distinctive lamination of the dense body. The electrondense lamellae run parallel to the long axis of the ribbon (Fig. 21). Lamellae are commonly seen in animals after the 10th postnatal day; they also were seen in thin plate ribbons in a 6-day culture. Lamellar substructure is easier to detect in underexposed pictures. Figures $17 \mathrm{C}$ and 20 are prints of the same negative. Figure 20 is an underexposed and magnified version of Figure $17 \mathrm{C}$. The la-

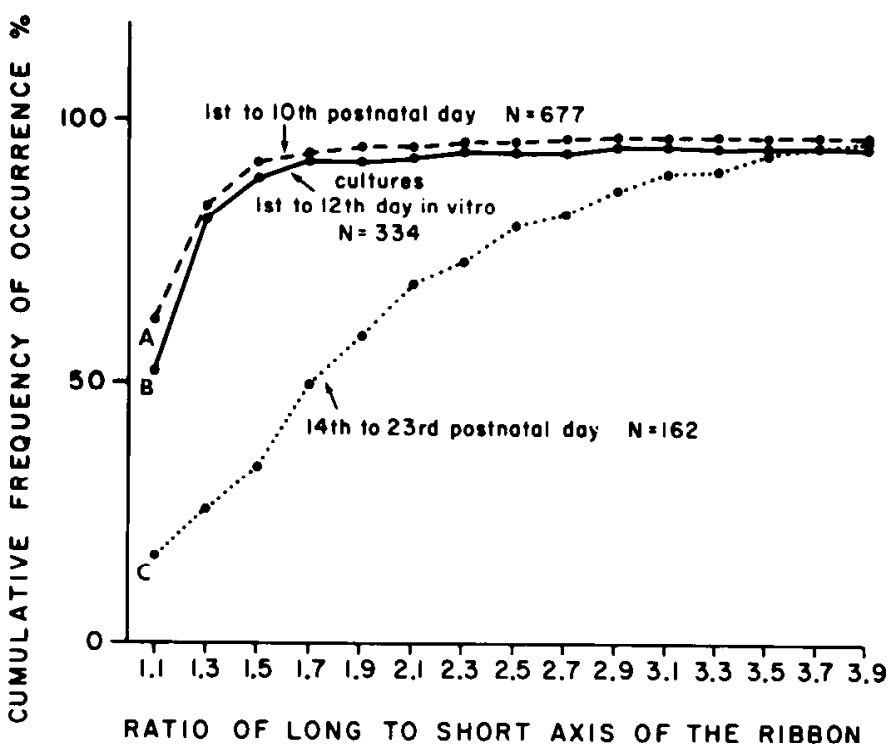

Figure 16. Shape of the ribbon profile expressed as a ratio of the long to short axis of the ribbon plotted against the cumulative frequency (percentage) of occurrence. Age is the parameter. In the first 10 postnatal days, most of the ribbons are roundish $(A)$; they are replaced by more elongated forms in adolescence $(C)$. $B$, Illustrating a sample of ribbons in cultured organ 1 to 12 days in vitro, closely resembles $A$.

mellar structure of the left ribbon, just detectable in Figure $17 C$, is obvious in Figure 20. Lamination is also apparent in ribbons in Figure 22.

The number of electron-dense lamellae per ribbon varies but is not less than three. The lamellar structure of the synaptic ribbons was described in thin plates of the retina (Gray and Pease, 1971; Matsusaka, 1967; Spadaro et al., 1978; Wagner, 1973) and in ampullary organs (Mullinger, 1969). More recently, Favre and Sans (1979) reported polylamellar ribbons in the vestibular hair cells in the newborn and adult cat, and Saito (1980) made a similar observation in the cochlear hair cells of the young adult guinea pig.

A curious, age-dependent feature in our material is a ring-like or a fenestrated ribbon (Figs. 17, 19, 22, 23, and

Figure 17. Serial sections ( $A$ to $E$ ) through a double ribbon synapse in a 16-day animal (apex). The synapse is located on a mound formed by the afferent fiber. The ribbon on the left is a plate, with a distinctly lamellar substructure. The substructure is seen well in Figure 20 which is an underexposed enlargement of Figure $17 C$. The right ribbon is fenestrated. Each ribbon is attached in a stalk-like fashion to a single presynaptic arcuate density that is separated from the presynaptic membrane by a fine electron-lucent line (Fig. 20, arrow). The ribbons sit in troughs formed by depressions of the presynaptic membrane. Single rows of synaptic vesicles adjoin the membrane on each side of the arcuate density. The postsynaptic membrane forms corresponding depressions accommodating the presynaptic troughs. The cleft is of uniform width. The scale in $A$ applies to all figures shown on the plate with the exception of Figures 20 and 21.

Figure 18. Ribbon with a central area that is lighter than the periphery in a 5-day animal (base).

Figure 19. Ribbon with a large electron-lucent center in an 18-day animal (apex). Synaptic vesicles can be seen in the clear area.

Figures 20 and 21 . Underexposed prints showing the details of afferent ribbon synapses in transverse and longitudinal section.

Figure 20. Synapse seen in cross-section (for description, see Fig. 17).

Figure 21. Synapse from an 18-day animal in longitudinal section (apex). The ribbon is attached to the presynaptic membrane by a cohesive sheet composed of fine strands.

Figure 22. Three laminated ribbons in a 14-day animal (apical midturn).

Figure 23. Ribbon synapse in an outer hair cell of a 14-day animal (apex). In contrast to the inner hair cell synapses, the afferent fiber arches toward the presynaptic complex, narrowing the cleft.

Figure 24. A tall plate ribbon with a light center in an 18-day animal (apex).

Figure 25. Serial sections $(A$ to $C$ ) through a large barrel-like ribbon in a 14-day animal. 

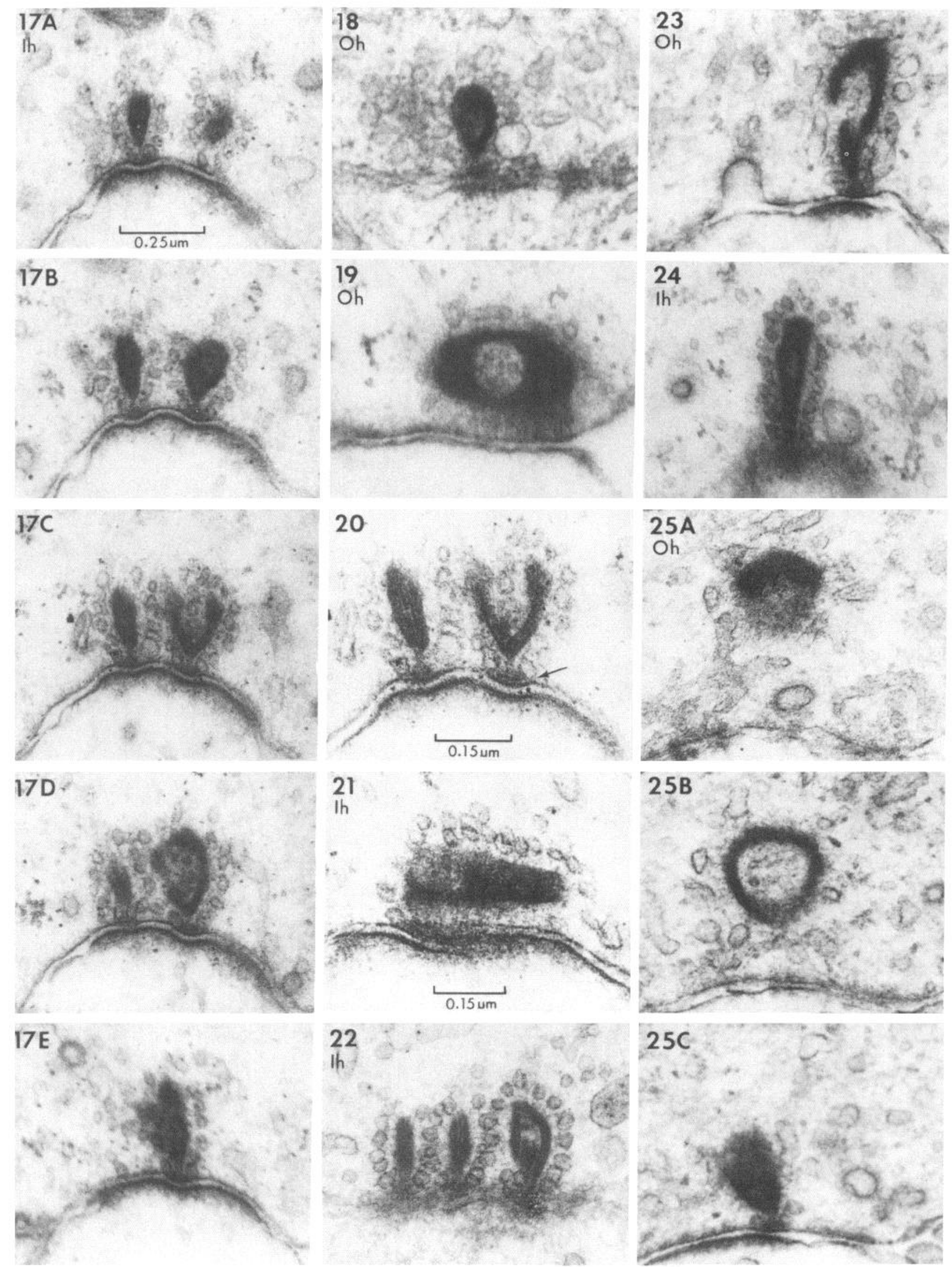

Figures 17 to 25 

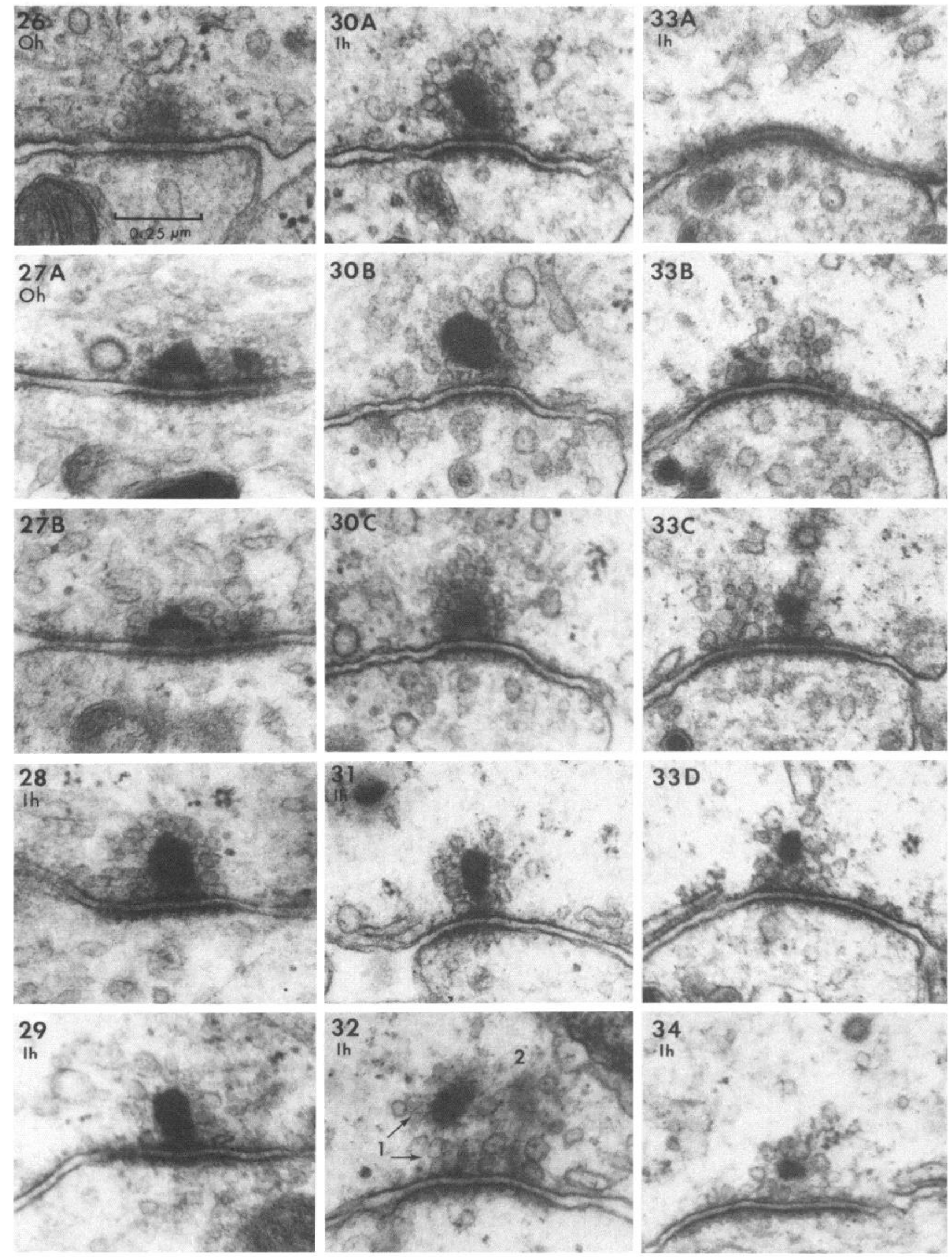
$25)$. Its formation is initiated, we believe, with the appearance of a slightly less electron-opaque area within the dense body. Ribbons showing a lighter area may be seen in young animals (Figs. $14 C$ and 18), whereas in older animals, ribbons with distinct electron-lucent centers appear (Figs. 19, 24, and 25). The size of the center varies. In some ribbons, the dense ring is very substantial (Fig. 19); in some, it appears mainly as a narrow band (Fig. 25B); while in others, the ring is incomplete and the ribbon appears fenestrated (Figs. 17, $C$ and $D$, and 23). Synaptic vesicles are seen sometimes within the hollow parts of the dense body. The figures suggest that these various forms may represent intermediate stages of the same process, which is possible related to the life cycle of the ribbon.

In contrast to the spheroid forms of young animals, the elongated ribbons of maturing hair cells display only a single presynaptic density. The density is separated from the presynaptic membrane by a narrow electron-lucent line (Fig. 20, arrow; compare with Fig. $3 A$ ) and closely resembles the arciform density described by Ladman (1958) in the retinal synapse.

As in the retina, the presynaptic membrane associated with the elongated ribbons forms a trough which accommodates the arcuate density and a row of vesicles at each side.

In cross-sections, elongated ribbons appear affixed in a stalk-like fashion to the arcuate ' nsity (Fig. 20). In suitable tangential sections, the attachment seems to form a coherent sheet of fine fibrous material (Fig. 21).

In add..ion to the arcuate density, the presynaptic membrane often displays a fuzzy coating that tends to parallel the postsynaptic specializations of the afferent fiber.

The postsynaptic specializations are conspicuous and somewhat different for the inner and outer hair cells. In conjunction with the inner hair cell, the postsynaptic segment of the afferent fiber forms a mound. A depres- sion, parallel to and coextensive with the presynaptic trough, is formed on the surface of the mound-an arrangement that results in a synaptic cleft of uniform width (Fig. 17). Such arrangements were not seen in conjunction with outer hair cells. A mound, if present, is minute (Fig. 23), and the width of the cleft is not uniform: the postsynaptic segment arches toward the presynaptic trough and narrows the cleft (Figs. 23 and $25 \mathrm{C}$ ). In the synapses of both inner and outer hair cells, the postsynaptic density is very prominent (Figs. 5, 17, 21, 23, and $25 C$ ). The areas of presynaptic fuzz and postsynaptic density may greatly exceed the territory of the ribbon (Figs. 17E, 19, and 25C).

Maturation of afferent synapses proceeds also in the isolated organ; in older cultures, features characteristic of both young and adolescent animals may occur concurrently (Figs. 26 to 34 ). As in the young developing animal, the shape of the ribbon varies from roundish (Fig. 34) to elongated (Fig. 31), and both double (Figs. 27 and $30 \mathrm{C}$ ) and single (Figs. 31 and 32) attachment sites may be seen. A discrete elevation of the afferent fiber (Figs. 30 and 32) and a slight undulation of both presynaptic and postsynaptic membranes are present occasionally (Figs. 29,32 , and 34 ), but in general, the synaptic membranes tend to be straight and parallel to each other (Figs. 26 and 28). The extent of the territory of the postsynaptic density and conspicuous presynaptic and postsynaptic fuzz are similar to those of the adolescent animal (Figs. 32 to 34 ).

In summary, the presynaptic and postsynaptic specializations appear to mature in culture at different rates. While the postsynaptic specializations develop pari passu with those of the intact animal, the development of the presynaptic complex seems to lag behind.

\section{Discussion}

Postnatal development of synaptic specializations. Our results indicate that a number of presynaptic and

Figures 26 to 34. Ribbon synapses in older cultures. Figures 26 to 30: 14 DIV, apex, M141-23; Figures 31 to 34: 24 DIV, apex, M149-7. The scale bar in Figure 26 applies to all figures shown on the plate.

Figure 26. Section through the vesicular cap of a ribbon in a 14-day culture. The postsynaptic segment of the afferent fiber is flat. Both the presynaptic and postsynaptic membranes are straight. The cleft is of uniform width.

Figure 27. Two consecutive sections $(A$ and $B)$ through a double ribbon synapse. The ribbon on the left has two attachments to the presynaptic membrane.

Figure 28. A roundish ribbon. Both membranes are straight. The postsynaptic density slightly exceeds the territory of the presynaptic complex. Note that the postsynaptic electron-dense material shows a number of small lumps at fairly regular intervals.

Figure 29. A spheroid ribbon. Both presynaptic and postsynaptic membranes are slightly wavy. The ribbon is attached to a single, somewhat arching, density.

Figure 30. Three consecutive sections $(A$ to $C$ ) through a roundish ribbon. Notice the double attachment to the presynaptic membrane $(C)$. There is a discrete mound-like elevation of the postsynaptic segment of the afferent fiber. The morphological details are very similar to those seen in a 9-day animal (Fig. 2).

Figure 31. Oval ribbon with a single attachment site. The advanced development of the presynaptic complex is accompanied, in this case, by a rather immature appearance of the postsynaptic membrane of the afferent fiber.

Figure 32. Double ribbon synapse; ribbons 1 and 2 share a postsynaptic density. Each ribbon shows a long single attachment to the presynaptic membrane. The attaching rodlet of ribbon 1 is interrupted. A single presynaptic density accompanies each ribbon. Note the vesicles alternating with the presynaptic rodlets. A slight depression of the presynaptic and postsynaptic membranes of ribbon 1, a slight elevation of the afferent fiber, and an extensive postsynaptic density suggest a rather advanced degree of synapse maturation in this culture.

Figure 33. Four consecutive sections $(A$ to $D)$ through a double ribbon synapse. The presynaptic fucz and postsynaptic density exceed the territory of the ribbon complex in all sections.

Figure 34. A small roundish ribbon. Note the extent of the postsynaptic density and the presence of distinct presynaptic fuzz. Both presynaptic and postsynaptic membranes are slightly wavy. 
postsynaptic specializations characterize the ribbon synapse in the organ of Corti of the mouse. Most of the specializations develop postnatally. Table I lists their appearance in the immature and adolescent cochlea of the intact animal. Some of the features signifying synapse maturation occur also in culture.

Some of the characteristics of the mature synapse, observed by us in the adolescent mouse, have been noticed in other adult mammals. Gulley and Reese (1977) described in the chinchilla a dome-shaped convexity of the afferent fiber, an arciform density, a trough formed by the presynaptic membrane, a corresponding depression of the afferent fiber, and presynaptic and postsynaptic fuzz. Most of these features were observed recently by Saito (1980) in the guinea pig.

It may be useful to recall that the mouse is born deaf. The first compound action potential can be recorded from the round window on the 9th day and from the eighth nerve a day later (Mikaelian and Ruben, 1965). The amplitude of the action potential increases up to the 14th day, with the largest increment appearing between

TABLE I

Comparison of some morphological features in the immature and adolescent cochlea

\begin{tabular}{|c|c|c|}
\hline & Immature Cochlea & Adolescent Cochlea \\
\hline Ribbon occurrence & Ih and $\mathrm{Oh}$ & Mainly Ih \\
\hline Ribbon shape & Spheroid & Plate \\
\hline Presynaptic densities & $\begin{array}{l}\text { Usually } 2 \text {, triangu- } \\
\text { lar }\end{array}$ & Single, arcuate \\
\hline Presynaptic membrane & Straight & $\begin{array}{l}\text { Concave, } \mathrm{Ih} ; \\
\text { convex, } \mathrm{Oh}\end{array}$ \\
\hline Presynaptic fuzz & Absent & Present \\
\hline Postsynaptic density & $\begin{array}{l}\text { Co-extensive with } \\
\text { ribbon }\end{array}$ & $\begin{array}{l}\text { Exceeding the } \\
\text { ribbon }\end{array}$ \\
\hline $\begin{array}{l}\text { Pattern of synaptic vesi- } \\
\text { cles on the membrane }\end{array}$ & $\begin{array}{l}\text { Single or double } \\
\text { patch }\end{array}$ & Two parallel rows \\
\hline
\end{tabular}

the 12th and 14th day (Mikaelian and Ruben, 1965). Behavioral data parallel electrophysiological findings (Ehret, 1977). It should be stressed, though, that individual spiral neurons may become electrically excitable in culture at least as early as the 6th day in vitro ( $\mathrm{S}$. Kuwada, J. E. Rose, H. M. Sobkowicz and J. E. Hind, unpublished observations). Our data are compatible with the presumption that the maturation of the afferent synapse is one of the factors that determine the onset of function in the organ of Corti.

Broadly speaking, synaptic ribbons in the cochlea of the mouse are either spheroids or plates of varying width. Spheroids are characteristic of the early developmental period. One of our leading observations is that, late in development, plate ribbons largely replace the spheroid forms.

Besides the cochlea, plate ribbons occur in the photoreceptors and bipolar cells of the vertebrate retina, in the electroreceptors of the ampullary organs, and in the receptors of the tuberous organs of some fishes. The plates in the organ of Corti are usually wider than the plates in mammalian photoreceptors.

Spheroid ribbons commonly occur in the vestibular cells of fishes and amphibians. Interestingly enough, in adult mammalian vestibular cells, spheroid forms occur only in type II receptors which usually are considered phyletically older (Wersäll et al., 1967). Spheroid ribbons in the type I cells appear only during development (Favre and Sans, 1979). Replacement of the spheroid forms by plate ribbons observed by us in cochlear hair cells of the mouse and by Favre and Sans in type I vestibular receptors of the cat supports the notion that the round ribbons may be phyletically older organelles.

Variations in shape seem to be related to the way that the ribbon is attached to the cell membrane. Typically, a spheroid ribbon is attached to two triangular densities by rodlets. Synaptic vesicles collect on the membrane
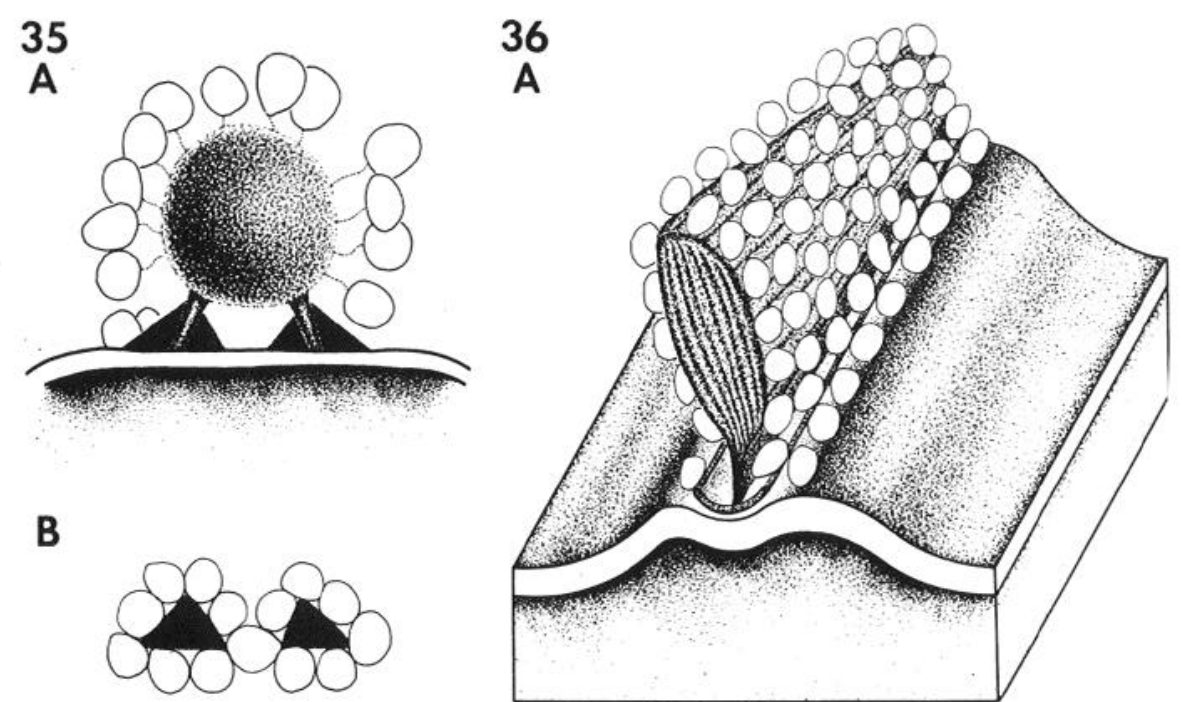

B

Figures 35 and 36 . Schematic representation of a round ribbon and its attachments in an immature cochlea (Fig. $35 A$ ) and of a plate ribbon in an adolescent animal (Fig. $36 A$ ). Figures $35 B$ and $36 B$ show the presumed pattern of synaptic vesicles on the presynaptic membrane. The space between the two triangular densities was left empty in Figure $35 \mathrm{~A}$ but is shown occupied by a synaptic vesicle in Figure $35 B$ in order to indicate the variations which may occur. 
around the presynaptic densities (Fig. 35). This mode of attachment is quite similar to that described by Osborne in the bullfrog labyrinth (Osborne, 1977; Osborne and Thornhill, 1972). Plate ribbons, on the other hand, are attached to a single arcuate density that sits in a trough formed by the presynaptic membrane (Fig. 36). At each side of the arcuate density, a row of vesicles is aligned parallel to the length of the ribbon. This mode of attachment in the organ of Corti seems identical to that suggested by Gray and Pease (1971) for the photoreceptors in the retina.

The actual number of attachments varies with different species and different receplors. Thus, Gleisner et al. (1973) depict, in the receptors of the frog labyrinth, round ribbons with three attachments to the presynaptic membrane. Hama and Saito (1977) described, in the vestibular receptors of the goldfish, round ribbons attached to the presynaptic membrane by means of four electron-dense rods, with rows of synaptic vesicles alternating with the anchoring bars. Flock (1965) observed five densities anchoring a single spheroid ribbon in the lateral line receptors of the teleost fish, burbot. Mullinger (1964) described multiple attachments of the spheroid ribbons in the electroreceptors of the small pit organs of the North American catfish Amiurus. The ribbons were anchored by as many as nine rodlets which appeared to originate from the ribbon body. As in the goldfish, the rows of synaptic vesicles alternated with the presynaptic rodlets.

Plate ribbons are, as mentioned, usually attached to a single arcuate density. However, in some ampullary organs, plate ribbons have multiple attachments. Thus, Mullinger (1969) and Szabo and Wersäll (1970) described, in the electroreceptors of electric fishes, ampullary plates that are supported by a series of presynaptic rodlets oriented perpendicularly to the long axis of the ribbon and separated from each other by a row of vesicles.

What the functional meaning of the various arrangements might be is unknown. It may be stressed though that, whatever the detailed structure, the electron-dense material of the ribbon usually is surrounded by synaptic size vesicles both in the retina and in all ribbons of statoacoustic organs. An alternating arrangement of vesicles and presynaptic structures seems to characterize ribbon synapses of many different receptors. It appears that the number and arrangement of presynaptic rodlets determines the pattern of synaptic vesicles on the presynaptic membrane, while the shape of the ribbon defines the extent of the active synaptic zone. In the cochlea of the adolescent mouse, the plate ribbon restricts the presynaptic zone to a grove extending through 3 to 4 sections and bounded by two rows of synaptic vesicles. A postsynaptic density characteristically exceeds the area of a presynaptic complex.

Distribution of synaptic ribbons. Little is known about the distribution of synaptic ribbons in the hair cells of different species. There seems to be general agreement that, in the mammalian organ of Corti, ribbons are components of all afferent synapses of the inner hair cells. Their presence in the outer hair cells seems less consistent. Thus, in the developing animal, ribbons were described in the outer hair cells of the rat (Lenoir et al., 1980), golden hamster (Pujol and Abonnenc, 1977), guinea pig (Thorn et al., 1972), cat (Pujol et al., 1979), and man (Igarashi and Ishii, 1980; Tanaka et al., 1979). In the outer hair cells of adult mammals, ribbons were observed in the mouse (Nakai and Hilding, 1968), guinea pig (Saito, 1980; Smith and Sjöstrand, 1961a, b), rhesus monkey (Kimura, 1975), and chinchilla (Siegel and Brownell, 1980; Smith, 1975). On the other hand, the outer hair cells of the adult rat (Lenoir et al., 1980; Pujol et al., 1980) and cat (Dunn and Morest, 1975; Pujol et al., 1.980) are reported to lack synaptic ribbons altogether.

In the mouse, the inner and outer hair cells show a similar number of synaptic ribbons during the first 5 postnatal days. However, during the next few days, the number of ribbons in the outer hair cells decreases to about $20 \%$ of the total population in a given age sample. A still larger developmental decrease was observed by Favre and Sans (1979) in type I vestibular cells of the guinea pig.

We conclude that, in early development, the probability of a ribbon occurrence is about the same for inner and outer hair cells, and the remarkable shift in ribbon distribution is a later postnatal event. In the intact animal, the decrease precedes the arrival of the efferent fibers; in culture, a similar decrease occurs in the organ devoid of efferent innervation. Evidently, reduction of the ribbon synapses in the outer hair cells results from interactions between the spiral neurons and the sensory cells without an obligatory participation of the efferent system.

Furthermore, our results indicate that local patterns of ribbon distribution may be regulated by the hair cell itself. Clustering of ribbons and formation of multiribbon synapses do not appear to be influenced directly by the presence of postsynaptic specializations or by the apposition of the nerve fiber to the cell membrane. The findings seem to indicate that: (1) the hair cell rather than the nerve fiber determines the occurrence and locus of the ribbon and (2) the presence of a ribbon tends to facilitate the occurrence of another ribbon in the immediate vicinity.

Until now, the clustering of ribbons was studied mainly in mammalian pinealocytes. The average life span of a ribbon in the pineal body (Vollrath, 1973) and in the retina (Spadaro et al., 1978) is $\sim 8 \mathrm{hr}$. Formation of ribbon fields in a pinealocyte follows the circadian rhythm; each field starts with the appearance of a single ribbon, subsequently followed by a cluster of new ones in the immediate vicinity of the original organelle.

In the cochlea, the occurrence of ribbon clusters appears characteristic of the early developmental period; however, in the mouse, double ribbon synapses persist at least throughout adolescence. It is tempting to speculate that the presence of a ribbon at the cell membrane triggers the appearance of a new ribbon, thus securing the synaptic site.

There is increasing evidence indicating that the ribbon may be a site for the storage of neurotransmitter or its precursors (Monaghan, 1975; Osborne, 1977; Osborne and Thornhill, 1972; Thornhill, 1972; Wagner, 1973). In our material, the occurrence of ring-like or fenestrated ribbons in the adolescent animals may indicate a perishable nature of cochlear ribbons. The less electron-dense center 
of some ribbons in the cochlear hair cells of the guinea pig was first noted by Smith and Sjöstrand (1961a) and recently by Saito (1980). Liberman (1980) found them in about half of the ribbon population of the inner hair cells in the cat. Ring-like ribbons in the hair cells of primates were observed by Kimura (1975) and Bodian (1978). Similar forms were seen in the vestibular hair cells of the squirrel monkey (Fngström et al., 1972) and guinea pig (Favre and Sans, 1979).

Whether ribbons with varied distribution and content of dense material represent organelles in different functional states is uncertain but, we believe, likely. Our observations seem to support the notion that a linited life span and cyclic renewal characterize ribbons not only in pinealocytes and photoreceptors but also in cochlear hair cells.

\section{References}

Barets, A., and T. Szabo (1962) Appareil synaptique des cellules sensorielles de l'ampoule de Lorenzini chez la 'T'orpille, 'Tor. pedo marmorata. J. Microsc. (Paris) 1: 47-54.

Bodian, D. (1978) Synapses involving auditory nerve fibers in primate cochleas. Proc. Natl. Acad. Sci. U. S. A. 75: $4582-4586$.

Boeckh, Y., C. Sandri, and K. Akert (1970) Sensorische Eingänge und synaptische Verbindungen im Zentralnervensystem von Insekten. Z. Zellforsch. Mikrosk. Anat. 103: 429-446.

Cohen, A. I. (1963) The fine structure of the visual receptors of the pigeon. Exp. Eye Res. 2: 88-97.

Derbin, C. (1970) Effets de la section du nerf latéral sur les jonctions sensorineurales des ampoules de Lonrenzini de la Torpille Torpedo marmorata. J. Microsc. (Paris) 9: 119-126.

Dowling, J. E. (1968) Synaptic organization of the frog retina: An electron microscopic analysis comparing the retinas of frogs and primates. Proc. R. Soc. Lond. (Biol.) 170: 205-228.

Dowling, J. E. (1974) Synaptic arrangements in the vertebrate retina: The photoreceptor synapse. Soc. Gen. Physiol. Ser. 28: 87-103.

Dowling, J. E., and B. B. Boycott (1965) Neural connections of the retina: Fine structure of the inner plexiform layer. Cold Spring Harbor Symp. Quant. Biol. 30: 393-402.

Dunn, R. A., and D. K. Morest (1975) Receptor synapses without synaptic ribbons in the cochlea of the cat. Proc. Natl. Acad. Sci. U. S. A. 72: 3599-3603.

Ehret, G. (1977) Postnatal development in the acoustic system of the house mouse in the light of developing masked thresholds. J. Acoust. Soc. Am. 62: 143-148.

Engstrom, H., B. Bergstrom, and H. W. Ades (1972) Macula utriculi and macula sacculi in the squirrel monkey. Acta Otolaryngol. Suppl. (Stockh.) 301: 75-126.

Favre, D., and A. Sans (1979) Morphological changes in afferent vestibular hair cell synapses during postnatal development of the cat. J. Neurocytol. 8: 765-775.

Fine, B. S. (1963) Synaptic lamellas in the human retina: An electron microscopic study. J. Neuropathol. Exp. Neurol. 22: 255-262.

Flock, §. (1965) Electron microscopic and electrophysiological studies on the lateral line canal organ. Acta Otolaryngol. Suppl. (Stockh.) 199: 7-90.

Foos, R. Y., W. Miyamasu, and E. Yamada (1969) Tridimensional study of an anomalous synaptic ribbon in human retina. J. Ultrastruct. Res. 26: 391-398.

Gleisner, L., and J. Wersäll (1975) Experimental studies on the nerve-sensory cell relationship during degeneration and regeneration in ampullar nerves of the frog labyrinth. Acta Otolaryngol. Suppl. (Stockh.) 333: 1-28.

Gleisner, L., §. Flock, and J. Wersäll (1973) The ultrastructure of the afferent synapse on hair cells in the frog labyrinth. Acta Otolaryngol. (Stockh.) 76: 199-207.

Gray, E. G., and H. L. Pease (1971) On understanding the organisation of the retinal receptor synapses. Brain Res. 35 : 1-15.

Guillery, R. W., H. M. Sobkowicz, and G. L. Scott (1970) Relationships between glial and neuronal elements in the development of long term cultures of the spinal cord of the fetal mouse. J. Comp. Neurol. 140: 1-34.

Gulley, R. L. and T. S. Reese (1977) Freeze-fracture studies on the synapses in the organ of Corti. J. Comp. Neurol. 171: 517-544.

Hama, K. (1965) Some observations on the fine structure of the lateral line organ of the Japanese sea eel, Lyncozymba nystromi. J. Cell Biol. 24: 193-210.

Hama, K., and K. Saito (1977) Fine structure of the afferent synapse of the hair cells in the saccular macula of the goldfish, with special reference to the anastomosing tubules. J. Neurocytol. 6: 361-373.

Igarashi, Y., and T. Ishii (1980) Embryonic development of the human organ of Corti: Electron microscopic study. Int. J. Pediatr. Otorhinolaryngol. 2: 51-62.

Kimura, R. S. (1975) The ultrastructure of the organ of Corti. Int. Rev. Cytol. 42: 173-222.

Krstić, R. (1976) Ultracytochemistry of the synaptic ribbons in the rat pineal organ. Cell Tissue Res. 166: 135-143.

Ladman, A. J. (1958) The fine structure of the rod-bipolar cell synapse in the retina of the albino rat. J. Biophys. Biochem. Cytol. 4: 459-466.

Lamparter, H. E., U. Steiger, C. Sandri, and K. Akert (1969) Zum Feinbau der Synapsen im Zentralnervensystem der Insekten. Z. Zellforsch. Mikrosk. Anat. 99: 435-442.

Lenoir, M., A. Shnerson, and R. Pujol (1980) Cochlear receptor development in the rat with emphasis on synaptogenesis. Anat. Embyrol. (Berl.) 160: 253-262.

Liberman, M. C. (1980) Morphological differences among radial afferent fibers in the cat cochlea: An electron-microscopic study of serial sections. Hear. Res. 3: 45-63.

Lissman, H. W., and A. M. Mullinger (1968) Organization of ampullary electric receptors in Gymnotidae (Pisces). Proc. R. Soc. Lond. (Biol.) 169: 345-378.

Lowenstein, O., and M. P. Osborne (1964) Ultrastructure of the sensory hair-cells in the labyrinth of the Ammocoete larva of the lamprey, Lampetra fluviatilis. Nature 204: 197-198.

Lues, G. (1971) Die Feinstruktur der Zirbeldrüse normaler, trächtiger und experimentell beeinflusster Meerschweinchen. Z. Zellforsch. Mikrosk. Anat. 114: 38-60.

Matsusaka, T. (1967) Lamellar bodies in the synaptic cytoplasm of the accessory cone from the chick retina as revealed by electron microscopy. J. Ultrastruct. Res. 18: 55-70.

Mikaelian, D., and R. J. Ruben (1965) Development of hearing in the normal CBA-J mouse. Acta Otolaryngol. (Stockh.) 59: 451-461.

Missotten, L. (1960a) Étude des synapses de la rétine humaine au microscope electronique. In The Proceedings of the European Regional Conference on Electron Microscopy, Vol II, pp. 818-821, De Nederlandse Vereniging voor electronenmicroscopie, Delft, Netherlands.

Missotten, L. (1960b) Étude des batônnets de la rétine humaine au microscope électronique. Ophthalmologica 140: 200-214.

Monaghan, P. (1975) Ultrastructural and pharmacological studies on the afferent synapse of lateral-line sensory cells of the African clawed toad, Xenopus laevis. Cell Tissue Res. 163: 239-247.

Mullinger, A. M. (1964) The fine structure of ampullary receptors in Amiurus. Proc. R. Soc. Lond. (Biol.) 160: 345-359.

Mullinger, A. M. (1969) The organization of ampullary sense organs in the electric fish, Gymnarchus niloticus. Tissue Cell 1: $31-52$. 
Nakai, Y., and D. A. Hilding (1968) Phosphotungstic acid staining of the organ of Corti for electron microscopy. Anat. Rec. 162: 1-14.

Osborne, M. P. (1966) The fine structure of synapses and tight junctions in the central nervous system of the blowfly larva. J. Insect Physiol. 12: 1503-1512.

Osborne, M. P. (1977) Role of vesicles with some observations on vertebrate sensory cells. In Synapses, G. A. Cottrell and P. N. R. Usherwood, eds., pp. 40-63, Academic Press, New York.

Osborne, M. P., and R. A. Thornhill (1972) The effect of monoamine depleting drugs upon the synaptic bars in the inner ear of the bullfrog (Rana catesbeiana). Z. Zellforsch. Mikrosk. Anat. 127: 347-355.

Pomés-Delaveuve, B. (1964) Particularités morphologiques de la région synaptique des cellules sensorielles des neuromastes du Goujon, Gobio fluviatilis. C. R. Acad. Sci. [D] (Paris) 258: 6222-6224.

Pujol, R., and M. Abonnenc (1977) Receptor maturation and synaptogenesis in the golden hamster cochlea. Arch. Otorhinolaryngol. 217: 1-12.

Pujol, R., E. Carlier, and C. Devigne (1979) Significance of presynaptic formations in early steps of cochlear synaptogenesis. Neurosci. Lett. 15: 97-102.

Pujol, R., E. Carlier, and M. Lenoir (1980) Ontogenetic approach to inner and outer hair cell function. Hear. Res. 2: 423-430.

Raviola, E., and N. B. Gilula (1975) Intramembrane organization of specialized contacts in the outer plexiform layer of the retina. J. Cell Biol. 65: 192-222.

Roberts, B. L., and K. P. Ryan (1971) The fine structure of the lateral-line sense organs of dogfish. Proc. R. Soc. Lond. (Biol.) 179: $157-169$.

Roth, A., and H. Tscharntke (1976) Ultrastructure of the ampullary electroreceptors in lungfish and Brachiopterygii. Cell Tissue Res. 173: 95-108.

Saito, K. (1980) Fine structure of the sensory epithelium of the guinea pig organ of Corti: Afferent and efferent synapses of hair cells. J. Ultrastruct. Res. 71: 222-232.

Siegel, J. H., and W. E. Brownell (1980) Synaptic bars in outer hair cells of the chinchilla cochlea. In Third Midwinter Research Meeting of the Association for Research in Otolaryngology, D. J. Lim, pp. 5-6.

Sjöstrand, F.S. (1958) Ultrastructure of the retinal rod synapses of the guinea pig eye as revealed by three-dimensional reconstructions from serial sections. J. Ultrastruct. Res. 2: 122-170.

Smith, C. A. (1975) The inner ear: Its embryological development and microstructure. In The Nervous System. Vol. 3: Human Communication and Its Disorders, D. B. Tower, eds., pp. 1-18, Raven Press, New York.

Smith, C. A., and F. S. Sjöstrand (1961a) A synaptic structure in the hair cells of the guinea pig cochlea. J. Ultrastruct. Res. 5: 184-192.

Smith, C. A., and F.S. Sjöstrand (1961b) Structure of the nerve endings on the external hair cells of the guinea pig cochled as studied by serial sections. J. Ultrastruct. Res. 5: 523-556.

Sobkowicz, H. M., B. Bereman, and J. E. Rose (1975) Organo- typic development of the organ of Corti in culture. J. Neurocytol. 4: 543-572.

Sobkowicz, H. M., J. E. Rose, G. L. Scott, S. Kuwada, J. E. Hind, D. Oertel, and S. M. Slapnick (1980) Neuronal growth in the organ of Corti in culture. In Tissue Culture in Neurobiology, E. Giacobini, A. Vernadakis, and A. Shahar, eds. pp. 253-275, Raven Press, New York.

Spadaro, A., I. de Simone, and D. Puzzolo (1978) Ultrastructural data and chronobiological patterns of the synaptic ribbons in the outer plexiform layer in the retina of albino rats. Acta Anat. (Basel) 102: 365-373.

Steiger, U. (1967) Uber den Feinbau des Neuropils im corpus pendunculatum der Waldameise. Z. Zellforsch. Mikrosk. Anat. 81: 511-536.

Szabo, T., and J. Wersäll (1970) Ultrastructure of an electroreceptor (mormyromast) in a mormyrid fish, Gnathonemus petersii. J. Ultrastruct. Res. 30: 473-490.

Szamier, R. B., and A. W. Wachtel (1970) Special cutaneous receptor organs of fish. VI. Ampullary and tuberous organs of Hypopomus. J. Ultrastruct. Res. 30: 450-471.

Takasaka, T., and C. A. Smith (1971) The structure and innervation of the pigeon's basilar papilla. J. Ultrastruct. Res. 35: 20-65.

Tanaka, K., and C. A. Smith (1978) Structure of the chicken's inner ear: SEM and TEM study. Am. J. Anat. 153: 251-272.

Tanaka, K., N. Sakai, and Y. Terayama (1979) Organ of Corti in the human fetus. Ann. Otol. Rhinol. Laryngol. 88: 749-758.

Thorn, L., J. Shinko, and R. Wetzstein (1972) Synaptic bar in the efferent part of a synapse in the organ of Corti. Experientia 28: 835 .

Thornhill, R. A. (1972) The effect of catecholamine precursors and related drugs on the morphology of the synaptic bars in the vestibular epithelia of the frog, Rana temporaria. Comp. Gen. Pharmacol. 3: 89-97.

Trujillo-Cenóz, O. (1969) Some aspects of the structural organization of the medulla in muscoid flies. J. Ultrastruct. Res. 27: 533-553.

Vollrath, L. (1973) Synaptic ribbons of a mammalian pineal gland. Circadian changes. Z. Zellforsch. Mikrosk. Anat. 145: 171-183.

Wagner, H. J. (1973) Darkness-induced reduction on the number of synaptic ribbons in fish retina. Nature New Biol. 246: 53-55.

Wersäll, J., A. Flock, and P. G. Lundquist (1965) Structural basis for directional sensitivity in cochlear and vestibular sensory receptors. Cold Spring Harbor Symp. Quant. Biol. 30: $115-132$.

Wersäll, J., L. Gleisner, and P. G. Lundquist (1967) Vestibular mechanisms: Fine structure. Ultrastructure of the vestibular end organs. Ciba Found Symp. 105-120.

Wolfe, D. E. (1965) The epiphyseal cell: An electron-microscopic study of its intercellular relationships and intracellular morphology in the pineal body of the albino rat. Prog. Brain Res. 10: 332-386.

Wood, M. R., K. H. Pfenninger, and M. J. Cohen (1977) Two types of presynaptic configurations in the insect central synapses: An ultrastructural analysis. Brain Res. 130: 25-45. 